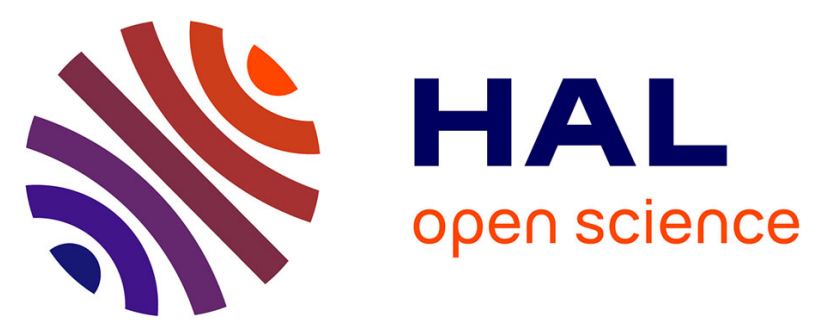

\title{
Automatic knot detection and measurements from X-ray CT images of wood: A review and validation of an improved algorithm on softwood samples
}

Fleur Longuetaud, Frédéric Mothe, Bertrand Kerautret, Adrien Krähenbühl, Laurent Hory, Jean Michel Leban, Isabelle Debled-Rennesson

\section{To cite this version:}

Fleur Longuetaud, Frédéric Mothe, Bertrand Kerautret, Adrien Krähenbühl, Laurent Hory, et al.. Automatic knot detection and measurements from X-ray CT images of wood: A review and validation of an improved algorithm on softwood samples. Computers and Electronics in Agriculture, 2012, 85, pp.77-89. 10.1016/j.compag.2012.03.013 . hal-00780761

\section{HAL Id: hal-00780761 https://hal.science/hal-00780761}

Submitted on 25 Jan 2013

HAL is a multi-disciplinary open access archive for the deposit and dissemination of scientific research documents, whether they are published or not. The documents may come from teaching and research institutions in France or abroad, or from public or private research centers.
L'archive ouverte pluridisciplinaire HAL, est destinée au dépôt et à la diffusion de documents scientifiques de niveau recherche, publiés ou non, émanant des établissements d'enseignement et de recherche français ou étrangers, des laboratoires publics ou privés. 


\title{
Automatic knot detection and measurements from X-ray CT images of wood: A review and validation of an improved algorithm on softwood samples
}

\author{
Longuetaud F. ${ }^{\mathrm{a}, \mathrm{b}, *}$, Mothe F., ${ }^{\mathrm{a}, \mathrm{b}}$, Kerautret B. ${ }^{\mathrm{c}}$, Krähenbühl A. ${ }^{\mathrm{c}}$, Hory L. ${ }^{\mathrm{c}}$, \\ Leban J.M. $^{\mathrm{d}}$, Debled-Rennesson I. ${ }^{\mathrm{c}}$ \\ ${ }^{a}$ INRA, UMR1092 LERFoB, 54280 Champenoux, France \\ ${ }^{b}$ AgroParisTech, UMR1092 LERFoB, 54000 Nancy, France \\ ${ }^{c}$ LORIA, UMR CNRS 7503, Université de Nancy \\ Campus Scientifique, 54506 Vandœuvre-lès-Nancy Cedex, France \\ ${ }^{d}$ ENSTIB, 88051 Epinal, France
}

\begin{abstract}
An algorithm to automatically detect and measure knots in CT images of softwood beams was developed. The algorithm is based on the use of 3D connex components and a 3D distance transform constituting a new approach for knot diameter measurements.

The present work was undertaken with the objective to automatically and non-destructively extract the distributions of knot characteristics within trees.

These data are valuable for further studies related to tree development and tree architecture, and could even contribute to satisfying the current demand for automatic species identification on the basis of CT images.

A review of the literature about automatic knot detection in X-ray CT images is provided. Relatively few references give quantitatively accurate results of knot measurements (i.e., not only knot localisation but knot size and inclination as well).

The method was tested on a set of seven beams of Norway spruce and silver
\end{abstract}

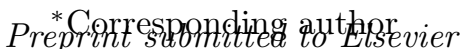

Email addresses: longueta@nancy.inra.fr (Longuetaud F.), mothe@nancy.inra.fr (Mothe F.), Bertrand.Kerautret@iutsd.uhp-nancy.fr (Kerautret B.), adrien057@gmail.com (Krähenbühl A.), yabb85@gmail.com (Hory L.), Jean-Michel .Leban@enstib.uhp-nancy .fr (Leban J.M.), Isabelle.Debled-Rennesson@loria.fr (Debled-Rennesson I.) 
fir. The outputs were compared with manual measurements of knots performed on the same images.

The results obtained are promising, with detection rates varying from 71 to $100 \%$, depending on the beams, and no false alarms were reported. Particular attention was paid to the accuracy obtained for automatic measurements of knot size and inclination. Comparison with manual measurements led to a mean $\mathrm{R}^{2}$ of $0.86,0.87,0.59$ and 0.86 for inclination, maximum diameter, length and volume, respectively.

Keywords: Branchiness, 3D distance transform, Computer tomography, Picea abies, Abies alba

\section{Introduction}

Wood knots are the prolongation within the tree stem of the branches. By linking the living crown where photosynthesis occurs, to the pith of the main stem and, finally, to the roots where the mineral nutrients are assimilated, branches and knots play a vital role in tree physiology. However, despite the fact that trees without branches do not exist, wood users would nevertheless like to obtain knot free lumbers. The frequency and size of the apparent knots are probably the first depreciation factors considered by wood suppliers for estimating the price of timber. This is also one of the main criteria considered in the visual grading of lumber.

The occurrence of knots within a piece of wood has several technological drawbacks, principally due to the deviation of the grain angle in and around the knots. Wood can be considered as an orthotropic material whose properties differ drastically along and across the grain. For example, the lon- 
gitudinal modulus of elasticity (along the grain) is typically ten times higher than the transverse one. From a mechanical point of view, this means that a knot within a wood beam may be assimilated to a hole. In wood machining, the quality of the surface around the knots is often depreciated due to the grain deviation while the life expectancy of tools may be severely shortened by shocks against the knots. Finally, knots usually depreciate the aesthetic quality of the wood as well.

Knowledge of knot geometry and location would be valuable in a sawmill for optimising cutting decisions or improving the grading of logs or lumber. CT scanners designed expressly for the wood industry are now available and some of the largest sawmills are now equipped with them. Such data are needed for studying tree architecture (Colin et al., 2010; Heuret et al., 2002; Passo et al., 2002; Meredieu and Caraglio, 1998), pruning (Seifert et al., 2010; Hein, 2008), branchiness (Colin and Houllier, 1991, 1992; Kershaw et al., 2009; Weiskittel et al., 2010; Courbet et al., 2007; Moberg, 1999; Meredieu et al., 1998) and knot morphology (Lemieux et al., 2001; Björklund and Petersson, 1999; Björklund, 1997; Lemieux et al., 1997; Samson et al., 1996; Samson, 1993). Branch and knot models for various species have been included into simulators for assessing wood quality (Houllier et al., 1995; de Coligny et al., 2003; Ikonen et al., 2009).

Observation of branch scars may help to assess the quality of a log but is not sufficient to predict its knottiness. Many knots linked to branches that were artificially or naturally pruned several years earlier may remain deeply hidden within the stem, notably at the lower part of old trees. Moreover, the knot shape from the outer branch insertion to the stem pith is a matter of 
guesswork.

$\mathrm{X}$-ray computer tomography has been recognised as being the most promising method to non-destructively analyse the internal structure of logs (Hailey and Morris, 1987; Chang, 1992; Schad et al., 1996). A review of the existing methods for automatically measuring knottiness on the basis of CT images is presented in the next section.

The objective of this paper was to propose an entirely automated method able to inventory knots from X-ray CT images of a piece of wood (round wood or beam) and to obtain data on knot geometry without any human intervention. Even if execution time was considered in the algorithmic choices, no special effort was devoted to speed optimisation. The first step of the algorithm, image segmentation, was not studied in details since a simple thresholding operation was efficient in the present case. On the contrary, special attention was paid to the validation step. Validation was performed on a large set of 428 knots using two software tools dedicated to (i) manual measurement of the knot shape on the CT images, and (ii) automatic matching of the manually measured and automatically detected knots. The challenges were to maximise the knot detection rate, to minimise the false alarms and to obtain an accurate and complete knot geometric description (including location, diameter, volume, inclination and shape descriptors).

The knot detection software was published under the GPL license and made available to the public (http://www . Ioria.fr/equipes/adage/3DKnotDM). 


\section{Review of existing methods to non-destructively and automati-} cally measure knottiness on the basis of CT images

This section is dedicated to the state of the art with respect to existing algorithms of knot detection based on the analysis of X-ray CT images. This review does not include some studies based on low-resolution images (for example, obtained from only two or three X-ray projections) performed in order to be more compatible with normal sawing speed (e.g., Pietikäinen, 1996; Flood et al., 2003). Indeed, comparison of accuracies with high-resolution images would have been of limited interest.

The first approaches of knot detection based on X-ray CT images found in the literature were developed in the 1980s.

Taylor et al. (1984) gave some general ideas for the detection of knots but without describing an algorithm in detail.

The first detailed description of an algorithm was given by Funt (1985), followed by Funt and Bryant (1987). A thresholding of the grey level histogram based on derivative methods was used to classify the pixels into four classes, where knots belong to the class with the highest density. Potential knot components were then represented by convex regions, and their size and orientation were analysed by the system in order to check whether they corresponded to actual knots or not: (i) components that were too small were eliminated on the basis of a size criterion; (ii) the orientation of each region was compared with the axis that passed through the pith and the centre of gravity of the region. Indeed, branches are connected to the stem pith where they have their biological origin and principal knot axes pass approximately through the pith. The 3D aspect of CT image stacks was not used in this 
approach and the authors do not give validation results.

In the 1990s an Australian research team proposed several interesting and original approaches for segmenting knots (Wells et al., 1991; Som et al., 1993, 1995; Davis et al., 1996), even if they do not seem to have finalised them. Validation results are therefore not provided.

A first approach (Wells et al., 1991) was based on vectors of statistical criteria computed in $5 \times 5$ neighbourhoods and on statistical methods applied to these vectors, such as principal component analysis.

A second approach (Som et al., 1993) consisted in applying edge detection and processing the resulting image with a $3 \times 3$ mask adapted to the radial structure of knots: if the local edge was oriented perpendicularly to a virtual line passing through the pith, then the pixel of interest was removed.

A third approach (Som et al., 1993) was based on subtractions of pairs of consecutive CT images. This method makes it possible to detect moving components such as knots from one CT image to another. A similar approach was used by Jaeger et al. (1999). This method is particularly efficient to remove sapwood when it is present. However, the method is strongly dependent on knot size and inclination and on the distance between two consecutive CT images (Longuetaud, 2005).

In a fourth approach (Som et al., 1995), the authors used mathematical morphology to detect breaks in the annual growth ring structure.

Zhu et al. provided an interesting algorithm based on a system of rules for defect detection in logs. They first applied low-level operations (filtering with a 3D Unser filter to eliminate annual rings and to preserve important image details, segmentation using a multi-thresholding scheme for $2 \mathrm{D}$ com- 
ponent identification, 3D volume growing) (Zhu et al., 1991b,a), followed by a high-level module (Zhu et al., 1991c,d), which consisted in a rule-based expert system for defect recognition. After selecting some features of interest (e.g., grey level mean value, distance to the centre of the log, volume), the authors computed confidence values for these features, depending on the wood characteristics. In Zhu et al. (1996), this part of the algorithm was refined by using the Dempster-Shafer theory of evidential reasoning. Visual results are provided for CT images of red oak and yellow poplar, but the authors do not give quantified accuracy results. Zhu and Beex (1994) tested another approach based on the application of spatial autoregressive modelling to wood-grain texture analysis.

Another original approach was developed by Grundberg and Grönlund (1992) for Scots pine logs. The main objective was to develop knot models ${ }^{1}$ in order to reduce the amount of data to be handled in their database (the Swedish Stem Bank) by saving only the model parameters obtained from automatic knot detection rather than pixel values. A low-pass filter was first applied to remove annual growth rings. The originality of the method was to work on concentric surfaces centred on the pith (manually detected) within $\operatorname{logs}$ (i.e., similar to surfaces obtained by rotary cutting logs). Knots were detected by thresholding (fixed threshold: $875 \mathrm{~kg} \cdot \mathrm{m}^{-3}$ ) five concentric surfaces located in the heartwood and by analysing overlapping between successive surfaces. The location of knots in the sapwood was predicted (not detected) by using models based on the previous detections in the heartwood. Vali-

\footnotetext{
${ }^{1}$ Models to predict tangential and longitudinal diameters and positions as functions of the radial distance to the pith.
} 
dation results are given based on 177 knots from five trees. The size and location of knots that were predicted on the most external concentric surface in the sapwood were compared with manual measurements. For their best tested model, five knots were missed, and means and standard deviations (SD in brackets) of predicted minus real knot diameters were $-2.55(4.74) \mathrm{mm}$ in the tangential direction and $-8.77(8.76) \mathrm{mm}$ in the longitudinal direction. Oja validated and adapted the previous algorithm for Norway spruce on two stems (Oja, 1996) and then applied it to $12 \operatorname{logs}$ (Oja, 2000). In addition, he provided some results about the detection of the sound knot/dead knot border. In this work, 80 to $100 \%$ of the knots larger than $7 \mathrm{~mm}$ were detected (94\% in average). Nine false knots were found in the 12 logs. The detection of knots was assessed by comparing real CT images and reconstructed CT images on the basis of the automatically estimated knot parameters. The accuracy of diameter measurements (at the dead knot border) was assessed on 27 knots based on comparisons between measurements on real boards and on reconstructed boards. The mean and SD of predicted (measured on reconstructed boards) minus real (measured on real boards) knot diameters were - $2(3) \mathrm{mm}$.

Nordmark (2003) later extended the Swedish Stem Bank with knot parameters estimated from knot detection in CT images of young Scots pine trees. The segmentation of knots in CT images (first step of the algorithm) was done by using the Artificial Neural Network (ANN) (see details below). Then, similarly to the previous associated works, concentric surfaces were used to identify knots in 3D and to fit knot models for size and position. The accuracy of the extracted descriptions was evaluated by comparing the size and 
position of knots measured on ten real boards from three trees with corresponding boards reconstructed on the basis of the descriptions. A total of $84 \%$ of 185 real knots was detected. The average and SD differences between simulated and real diameters in tangential and longitudinal directions were $0.6(4.0) \mathrm{mm}$ and $-0.6(3.9) \mathrm{mm}$, respectively.

In these studies, the CT slice thickness was $5 \mathrm{~mm}$ and the distance between two consecutive slices was $5 \mathrm{~mm}$ for pine logs and $10 \mathrm{~mm}$ for spruce logs and young pine logs. The resolution was approximately $1.37 \mathrm{~mm} \cdot$ pixel $^{-1}$ for young pine logs.

In our opinion, Bhandarkar et al. $(1996 ; 1999)$ gave the most finalised algorithm that we found in the literature. The first step consisted in the segmentation of CT images in four pixel classes (the knots belonged to the class with the highest density) by using a complex form of an area-based multiple thresholding algorithm. The algorithm then located the pith, grouped the pixels of the segmented images on the basis of their $2 \mathrm{D}$ connectivity (region-growing process), deleted regions that were too small, and classified each 2D region as a defect-like or defect-free region by computing shape, orientation and morphological features (considering, for example, like Funt and Bryant (1987), that knot principal axes pass approximately through the stem pith). 2D regions were then represented by convex hulls, and holes were filled. Finally, the 2D regions with adequate 3D support were labelled as true defects. Knot parameters such as knot inclination and slenderness were then computed from these 3D regions and helped to remove invalid knot regions. White ash, red oak, black walnut and hard maple logs were analysed. Defects were manually identified and delineated in colour images of 
real cross-sections to enable comparisons with the corresponding automatic detections in CT images. The numbers of knots considered were 225, 161, 330 and 194 for white ash, red oak, black walnut and hard maple, respectively. Detection rates were between $80.8 \%$ for red oak and $89.3 \%$ for white ash, and false alarm rates were between $5.1 \%$ for red oak and $12.7 \%$ for hard maple. Localisation accuracies were given in terms of centroid displacement, orientation difference and overlap factor.

More recently, Bhandarkar et al. (2006; 2008) proposed a novel approach based on Kalman filter-based tracking algorithms. The defects were simultaneously detected, classified, localised and reconstructed in 3D. The results were promising with detection rates of $100 \%$ obtained for white ash, hard maple and red oak logs.

Andreu and Rinnhofer (2003a; 2003b) proposed a method to detect knots in CT images of Norway spruce logs. Like Grundberg and Grönlund (1992) earlier, they aimed to represent knots by parametric functions. First, the pith was detected in CT images. Then, a multi-modal histogram thresholding method was applied to classify the pixels into four classes, after several image pre-processing steps (e.g., annual ring structure removal by Gaussian filtering). The 2D knot areas that were detected on successive images were then grouped together, based on their distance to the pith and the direction of their principal axis in the $\mathrm{CT}$ image plane, in order to obtain a 3D support from which knot models were fitted (3D curve along which the $2 \mathrm{D}$ cross-section is swept). The validation was done based on four logs by making comparisons between knots that were visible on real boards and on corresponding virtual boards obtained on the basis of the knot models. 


\footnotetext{
${ }^{2}$ These figures are probably means and SD of differences in "automatic minus manual measurements", but this was not specified by the authors.
} 
Other approaches based on classification methods focused mainly on the segmentation of knots (and often other wood characteristics) in CT images. The results were then expressed as percentages of correctly classified pixels. Hagman and Grundberg (1995) tested two classification methods (backpropagation Artificial Neural Network (ANN) and Partial Least Squares modelling) in order to separate knots from clearwood in CT images and to distinguish between four types of knots (sound knots in sapwood, dry knots in sapwood, sound knots in heartwood and rotten knots in sapwood). The accuracies were between $85 \%$ and $97 \%$ of correctly classified pixels (based on 163 knots). The two methods tested gave equal results.

Li et al. (1996), He (1997) and Schmoldt et al. (1996; 1998b; 1998a) also used a back-propagation ANN to detect wood characteristics in CT images of two species of oak (Quercus rubra L. and Quercus nigra L.), yellow poplar and black cherry. For each pixel in the image, the network took the values of pixels in $5 \times 52 \mathrm{D}$ or in $3 \times 3 \times 33 \mathrm{D}$ neighbourhoods as input, as well as the distance of the target pixel to the centre of the log. Species-dependent and species-independent classifiers were tested. As output, the target pixel was associated with a wood characteristic (which included knots). All tested classifiers had accuracies above 90\% (above 95\% for all species-dependent classifiers). Improvements by post-processing based on mathematical morphology were suggested by the authors and one specific approach was proposed by Sarigul et al. (2003).

Nordmark also used feed-forward back-propagation ANN for segmenting knots in CT images of a 30-year-old Scots pine (Nordmark, 2002). The objective was to enlarge the Swedish Stem Bank with young trees with a small propor- 
tion of heartwood because the algorithm previously described by Grundberg and Grönlund (1992) was not adapted to that case. ANN was used here as the first step of a more complete algorithm including parametrical descriptions of knots (Nordmark, 2003) (see above). The ANN was trained using five images taken at different heights from each of five trees. The ANN inputs were a $9 \times 9$ neighbourhood, oriented in the radial direction, and the distance of the target pixel to the pith (manually located). They obtained $95.9 \% \pm 1.2 \%$ of correctly classified pixels (cross-validation method).

Rojas et al. $(2005 ; 2006)$ tested two parametric supervised classification algorithms to detect wood characteristics in sugar maple logs: a minimum distance classifier (MDC) and a maximum likelihood classifier (MLC). They used five logs (1.5 m long) from one single freshly cut tree (group 1) and three logs from a sawmill yard (group 2). A total of 125 and 90 CT images were analysed for group 1 and 2, respectively. Confusion between coloured heartwood and knots was observed for both groups. It should be noted that the authors were more interested in detecting sapwood (for which accuracies were better) than knots because it is a key factor for determining sugar maple lumber value. The overall accuracies were $83.1 \%$ (MDC) and $82.6 \%$ (MLC) for group 1 (evaluation of $25 \mathrm{CT}$ images), and $76.4 \%$ (MDC) and $78.0 \%$ (MLC) for group 2. Regarding knots, correctly classified pixels were $64.8 \%$ (MDC) and 61\% (MLC) for group 1, and 47.4\% (MDC) and $44.7 \%$ (MLC) for group 2. The slice thickness was $5 \mathrm{~mm}$ and the resolution was between 0.6 and 0.9 mm.pixel ${ }^{-1}$.

More recently, Wei et al. (2008a; 2008b; 2009) tested both back-propagation ANN and MLC in order to identify internal wood characteristics (which in- 
cluded knots) in sugar maple and black spruce logs. They tested a faster converging algorithm for the ANN. Nine image features were used as input of both classifiers: grey level values, the distance between the pixel of interest and the pith, and seven textural features (homogeneity, contrast, dissimilarity, mean, SD, entropy and angular second moment). The validation was done by comparison with manually delineated characteristics in $20 \mathrm{CT}$ images (Wei et al., 2009). The overall accuracies for the MLC classifier and for the ANN were $80.9 \%$ ( $78.3 \%$ for knots) and $97.6 \%$ (95.5\% for knots), respectively (Wei et al., 2009).

\section{Materials and methods}

\subsection{Sampling}

The knot detection software was applied to a set of seven squared beams $(25 \mathrm{~cm} \times 25 \mathrm{~cm} \times 300 \mathrm{~cm})$ of silver fir (Abies alba Mill.) and Norway spruce (Picea abies (L.) Karst.). The beams, courtesy of the sawmill, Ets. Siat-Braun (Alsace, France), were selected at random in the lumber yard in which the two species are undifferentiated. After macroscopic identification, it was found that there were four beams of fir (\#1 to \#4) and three beams of spruce $(\# 5$ to $\# 7)$. The beams were air-dried several weeks before the measurements were taken.

\subsection{CT scanning}

The samples were analysed using an X-ray scanner device (BrightSpeed Excel by GE Healthcare) designed for medical use. The piece of wood is translated at approximately $2 \mathrm{~cm} / \mathrm{s}$ across a ring (gantry) around which 
the X-ray tube and the detector rotate. A volumetric reconstruction of the sample is delivered almost instantaneously in the form of a stack of $512 \times$ 512 images. The grey-level images are expressed in Hounsfield units that may be converted to wood density by simple linear regression (Freyburger et al., 2009). In the present study, six of the seven beams were scanned with the X-ray generator set to $120 \mathrm{kV}-50 \mathrm{~mA}$, and a slice thickness and interval between slices of $3.75 \mathrm{~mm}$. Beam \#1 was previously scanned with the generator set to $120 \mathrm{kV}-80 \mathrm{~mA}$, the slice thickness to $1.25 \mathrm{~mm}$, and the interval between slices to $1 \mathrm{~mm}$ (which means that there was overlapping between slices). For cost reasons, beam $\# 1$ was not scanned again with exactly the same settings as the six other beams. The image reconstruction of the beams was performed using a DETAIL filter ${ }^{3}$ with a pixel size of 0.74 $\mathrm{mm} \times 0.74 \mathrm{~mm}$. Since the scanner can only process $1.50 \mathrm{~m}$-long pieces, the beams were scanned in two passes.

\subsection{Manual knot measurements}

The knot shape and size were manually recorded using ImageJ software (Rasband, 2010) and a plug-in dedicated to the analysis of internal tree architecture by X-ray CT scanning (Gourmands plug-in described in Colin et al. (2010)). The operator reviews the image stack and manually places markers along both sides of each branch, starting from the pith and progressing towards the external end. The distance between the two lines of markers gives the diameter profile of the knot in the plane perpendicular to the main axis of the beam, assuming a circular cross section. The trajectory of the pith

\footnotetext{
${ }^{3}$ One of the seven reconstruction filters available with the scanner software.
} 
is also recorded using specific markers. The software makes it possible to compute and export the geometrical description of each measured knot. The following variables were used in this study to characterise each knot:

- Starting point (SP) and end point (EP): first marker near the pith and mid-point of the last two markers;

- Length: distance from SP to EP;

- Inclination: angle between the horizontal plane and the SP to EP line ${ }^{4}$;

- Azimuth: horizontal angle between a given axis and the SP to EP line;

- Maximum diameter;

- Volume: estimated by summing the volumes of truncated cones defined by the marker lines.

These measurements are subjective. The operator has to decide which singularities correspond to a knot and the exact location of the knot boundaries. For the purpose of standardising the measurements, the operator was asked to only consider knots for which pith (the secondary pith of the branch) was visible and to adjust the grey-level contrast to a fixed range $(-1000$ to +200 Hounsfield units).

Figure 1 illustrates the variability encountered in the samples studied for knot size and shape.

$* * * * *$ Figure 1 about here ${ }^{* * * * *}$

\footnotetext{
${ }^{4}$ assuming that the beam longitudinal axis is vertical
} 
3.4. Algorithm for automatic knot detection and measurements

\subsubsection{Description}

- Data input

The images created by a medical CT scanner device are stored in DiCoM format with grey levels expressed in Hounsfield numbers $(\mathrm{H})$, which are calibrated in such a way that Hounsfield numbers measured on air and water have a value of -1000 and 0 , respectively.

- Pith detection

An initial thresholding with a fixed value of $-700 \mathrm{H}\left(\simeq 300 \mathrm{~kg} \cdot \mathrm{m}^{-3}\right)$ was applied for removing the background. The pith was then detected on each CT image of a beam by using the algorithm described in Longuetaud et al. (2004). Briefly, the algorithm is based on a Hough transform method and virtually draws lines perpendicular to the annual growth rings, looking for a maximum of accumulation with respect to the number of intersecting lines. The pith location is estimated by linear interpolation in CT images including knots, for which no clear maximum of accumulation is found.

- Knot segmentation

A thresholding was used to segment knots. The threshold value was selected based on the grey level histogram, smoothed by Loess local polynomial fitting, by searching for the rightmost minimum or inflexion point in a region ranging from -300 to $100 \mathrm{H}\left(\simeq 700\right.$ to $\left.1100 \mathrm{~kg} \cdot \mathrm{m}^{-3}\right)$.

- Connex components (3D) 
Since the memory size of the whole 3D image can be very large, we defined a strategy that made it possible to save memory space while maintaining efficient extraction of connected components. The 3D image was processed slice-by-slice while maintaining the set of connected components in memory.

$* * * * *$ Figure 2 about here ${ }^{* * * * *}$

Figure 2 illustrates the main idea of the algorithm. Only the current and previous slices (represented in red) are stored in the system memory. From each processed voxel (in blue), the list of connected components is maintained by analysing the 26-connected neighbourhood (illustrated in cyan).

- Processing of each component:

- Convex hull (2D)

The Graham scan algorithm was used to compute the convex hull of the pixels belonging to the component in each slice. A holefilling algorithm was then applied to fill the polygons.

- Distance transform (3D)

The distance transform applied to a 3D space makes it possible to compute the minimal distance between any point and the object surface. To perform such a transformation, the algorithm of Saito and Toriwaki (1994) was applied to each connected component. 
An example of a distance transform is illustrated in Fig. 3 with a real knot. The points around the surface of the object are at distances close to 0 , represented in shades of red, while the farthest points are represented in shades of blue.

$* * * * *$ Figure 3 about here $* * * * *$

- Principal component analysis (3D)

The three inertia axes of the component were computed by applying a principal component analysis to the set of 3D coordinates of the voxels belonging to the component.

\subsubsection{Outputs}

For each 3D component, the following data were computed (Fig. 4):

- Starting and end points: 3D coordinates of the first and last points of the component projection onto the principal inertia axis. The starting point is the closest to the pith;

- Length: distance from the starting point to the end point;

- Inclination: angle between the horizontal plane and the principal inertia axis $^{5}$. Mathematically, it ranges from $-90^{\circ}$ to $90^{\circ}$. A null value means that the component is horizontal; inclination is positive or negative when the component goes up or down, respectively;

\footnotetext{
${ }^{5}$ Assuming that the beam longitudinal axis is vertical.
} 
- Elongation: ratio between the second and first eigenvalues of the 3D principal component analysis. Mathematically, it ranges from 0 to 1 with values close to 0 for very elongated components;

- Radial deviation angle (RDA): angle between the horizontal projection of the principal inertia axis and the horizontal axis linking tree pith to the centre of gravity of the component. Mathematically, it ranges from $-90^{\circ}$ to $90^{\circ}$. A null value means that the component has a radial orientation; values near $90^{\circ}$ or $-90^{\circ}$ mean that the component axis is perpendicular to the radial direction;

- Azimuth: angle between the horizontal projection of the principal inertia axis and a given horizontal axis in the beam coordinate system;

- Maximum diameter: maximal value of the distance-transformed component;

- Volume: product of the number of voxels belonging to the component with the volume of a voxel;

$$
* * * * * \text { Figure } 4 \text { about here }{ }^{* * * * *}
$$

On the basis of these output variables, some criteria were established in order to identify the 3D components corresponding to actual knots. Details about criteria computation are given in Section 3.5.

\subsubsection{Software implementation}

The 3DKnotDM software was implemented in $\mathrm{C}++$ language and was tested on different platforms such as Linux and Mac OS X. Several common 
libraries were included in the development to perform efficient functionality. The main architecture is based on the QT (2011) Development Frameworks, which was combined with the use of the LibQGLViewer (2011) library for the 3D display part. The DiCoM image files were read using the Grassroots library (Malaterre, 2008). The Armadillo library (Sanderson, 2010) was used to process the $3 \mathrm{D}$ image matrix and to perform the 3D principal component analysis. Finally, the DGtal (2011) library was also included to perform efficient surface extraction from the discrete set of surface elements (surfels).

\subsection{Calibration and statistical validation}

A cross-validation approach of the "leave-one-out" type was used. The 3D components of one single beam were used as the validation data set and the knots of the six other beams as the calibration data set. The procedure was repeated until each beam had been used as a validation data set.

\subsubsection{Calibration}

The calibration procedure mainly consisted in defining criterion bounds for deciding whether an automatically detected 3D component was a knot or not.

Three criteria were used and were defined on the basis of the biologic knowledge about knots: inclination, elongation and RDA of the 3D components (details about the computation are given in Section 3.4.2). Spruce and fir knots are slightly tilted and preferentially up oriented. Knots are characterised by an elongated shape. Biologically, knots are connected to the pith and their principal axis intersects the pith line. 
First, the observations used for calibration were defined as the 3D components belonging to the calibration data set that most likely corresponded to actual knots. This was done by searching the 3D component, when it existed, that was the closest to each manually delineated knot within a window $40^{\circ}$ wide in azimuth $\left(20^{\circ}\right.$ on each side of the actual knot) and $40 \mathrm{~mm}$ high in the longitudinal direction (20 $\mathrm{mm}$ above and below the actual knot). In addition, among these components, only the ones with diameter and inclination sufficiently close to the manual measurements were retained. This was done by computing the corresponding residuals and by removing the $3 \mathrm{D}$ components whose residuals were identified as outliers. Outliers were detected on the basis of the classical criterion used in the boxplot statistical method (Zuur et al., 2010). The 3D components for which the corresponding pith location was not correctly detected were removed, based on the same criterion. Finally, the number of observations used for calibration are indicated in Table 1 for each single beam when it was used for validation.

The second step was to define upper bounds for each criterion based on the calibration observations. Statistical distributions were fitted from the observed distributions of the criteria. The theoretical distributions were chosen on the basis of their shape and support. Our goal was to approximate the maximal possible value of each criterion. A Weibull distribution (support on $[0 ;+\infty[)$ was fitted to the absolute value of the tangent of the inclination. The absolute value was used because the signed value would have depended on the beam orientation, which is not always easy to assess (Fig. 1), particularly in the case of an industrial process. A beta distribution (support on $[0 ; 1])$ was fitted to the elongation criterion. Once again, a Weibull distri- 
bution was fitted to the absolute value of the tangent of the RDA. For each criterion, based on the fitted distribution, the quantile corresponding to $\mathrm{p}=$ 0.999 was chosen as the upper bound. Table 1 gives the upper bounds that were obtained from the calibration data sets and then used on the respective validation data sets. For an application of the algorithm to other logs or beams, the upper bounds would be the means of the values given in Table 1 for the seven beams. Hence, the overall upper bounds would be: $53.1^{\circ}$ for the inclination, 0.25 for the elongation criterion and $15.9^{\circ}$ for the RDA.

$$
\text { *****Table } 1 \text { about here }{ }^{* * * * *}
$$

\subsubsection{Validation}

The observations used for validation were defined as being the 3D components belonging to the validation data set that had been identified as being knots by the algorithm based on the three criteria described above. For validation purposes, it was necessary to establish a correspondence with manual knot measurements. This was done by searching the 3D component, when it existed, that was the closest to each manually delineated knot within a window $40^{\circ}$ wide in azimuth and $40 \mathrm{~mm}$ high in the longitudinal direction.

The validation of the algorithm was performed on the basis of several criteria and aimed at both quantitatively and qualitatively assessing the knot detection. We were interested in the percentage of detected knots and in the rate of false alarms, depending on the knot size. We were also interested in the measurement accuracy for the following variables that were available among the manual measurements: inclination, maximum diameter, length and volume. Since the correspondences between automatic and manual detections were looked for within windows restricted in azimuth and height, it 
would not have been relevant to analyse the accuracy for azimuth and height of insertion. For assessing accuracy, the following criteria were computed: r-square $\left(\mathrm{R}^{2}\right)$, root-mean-square error (RMSE), mean of errors (i.e., automatic minus manual measurements) and standard deviation of errors. Plots of manual measurements vs. automatic measurements were drawn for each variable by tree species (Mayer and Butler, 1993).

$\mathrm{R}$ statistical software was used for all computations included in Section 3.5 (R Development Core Team, 2009).

\section{Results}

\subsection{Detection rate}

Table 2 shows the detection rates observed for each beam. Depending on the sample, 71 to $100 \%$ of the measured knots were detected $(85 \%$ over the whole data set). Figure 5 shows an example of a correctly detected whorl of knots.

$$
\begin{aligned}
& * * * * * \text { Table } 2 \text { about here } * * * * * \\
& * * * * * \text { Figure } 5 \text { about here }{ }^{* * * * *}
\end{aligned}
$$

The observation of the 63 missing knots showed that only five of them were really missing in the set of components delivered by the algorithm. In the other cases, a component was actually delivered but either (i) not associated with the measured knot (one case only), or (ii) not identified as a knot due to the merging of several knots within the same component. Knot merging was observed near the pith for 21 knots, 15 of which belonged to beam $\# 7$, probably due to the presence of denser compression wood around 
the pith (Fig. 6). Merging was also observed for 28 knots of beams \#3 and \#4 due to wet areas (Fig. 7). In both cases, the merged components were logically rejected with respect to the elongation or orientation criteria, resulting in lower detection rates.

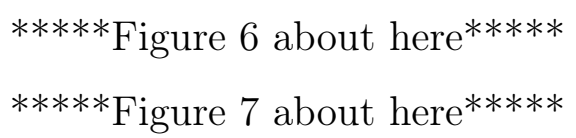

The fourth column of Table 2 gives the number of components that were considered as knots by the automatic algorithm but not associated with a manually measured knot. Careful observation of the CT slices showed that all of the 149 supplemental components actually corresponded to a knot or a bud trace. In most cases, the knot was not measured because of its small size; some other knots were measured but delivered several fragments from which only one was associated with the knot.

Figure 8 shows the distributions of detected knots (manually measured or not) and missing detections by diameter classes. In particular, it may be observed that the algorithm was able to detect more knots than the operator for the smallest diameters. Indeed, the operator was asked not to measure the very small branches for which the pith was not visible. The proportion of missing detections was relatively low, regardless of the diameter class.

$$
\text { *****Figure } 8 \text { about here }{ }^{* * * * *}
$$

\subsection{Detection accuracy}

The accuracy of the automatic measurements was analysed on the basis of the 365 detected knots for which manual measurements were available. 
The variables that were considered for accuracy were: inclination, maximum diameter, length and volume of knots.

Figure 9 shows plots of manual vs. automatic measurements for each of these four variables compared to the $\mathrm{Y}=\mathrm{X}$ line. $\mathrm{R}^{2}$, RMSE, mean of errors and standard deviation of errors are given for each single beam in Table 3 .

Regarding inclination measurements, the mean RMSE was $4.5^{\circ}$. The results were globally satisfactory with a mean $\mathrm{R}^{2}$ of 0.86 . The least accurate results were obtained for beam $\# 6$ with a RMSE of $6.9^{\circ}$ and inclinations underestimated by the algorithm, especially for the two branches that were the most bottom oriented. Like beams $\# 1$ and $\# 7$, beam \#6 had the particularity of having its knots quite horizontal and even bottom oriented (Fig. $1)$.

Regarding the diameter measurements, the mean RMSE was $3.4 \mathrm{~mm}$. The results were globally satisfactory with a mean $\mathrm{R}^{2}$ of 0.87 . The least accurate results were obtained for beams \#6 and \#7 with RMSE of 5.3 and $4.4 \mathrm{~mm}$, respectively. This was due to the biggest branches for which the maximum diameter was underestimated by the algorithm. In addition, a slight bias was observed for most of the beams, with automatically measured diameters often smaller than the manually measured ones. Beam \#6 had the particularity of having bigger knots than the other beams and a quite high variability of knot maximum diameters. The averages of mean errors and standard deviations were $-1.8(2.9) \mathrm{mm}$.

Regarding the length measurements, the mean RMSE was $3.3 \mathrm{~cm}$. This was the variable that was the least accurately measured by the algorithm, with a mean $\mathrm{R}^{2}$ of 0.59 . The least accurate results were obtained for beam 
613

\#2 with a RMSE of $5.2 \mathrm{~cm}$. A bias was observed for all of the beams since automatically measured lengths were generally shorter than the manually measured ones. Figure 10 shows that the biggest errors essentially occurred for knots with small diameters that sometimes led to fragmented 3D components due to the thresholding.

Regarding the volume measurements, the RMSE for all the beams together was $12.0 \mathrm{~cm}^{3}$. The results were satisfactory with a mean $R^{2}$ of 0.86 , except for beam \#7 (RMSE of $20.0 \mathrm{~cm}^{3}$ ), essentially due to two branches for which the volumes were overestimated by the algorithm.

For knot diameter and length, no difference in accuracy was observed between spruce and fir. For knot inclination and volume, the results were slightly better for fir than for spruce (statistically assessed by t-tests).

The moisture content of the beams (not controlled here) was probably an important factor in relation to the accuracy of the automatic measurements since wood density was similar for knots and wet wood areas, which led to some problems in the automatic detection.

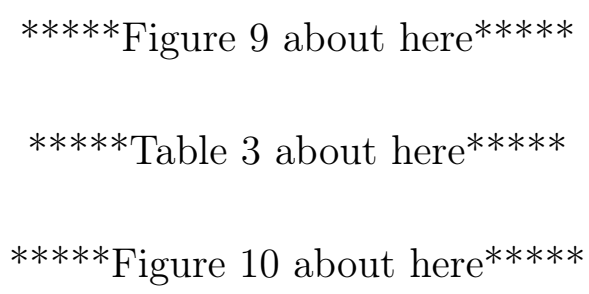

\section{Discussion}

When aiming to analyse the distributions of knot characteristics within trees (e.g., Colin and Houllier, 1992; Kershaw et al., 2009; Weiskittel et al., 2010), it is particularly important to identify and accurately measure each 
knot individually. Such data are particularly valuable for studying tree development and tree architecture, and for linking tree growth conditions to wood quality. In addition, there is a demand for the development of automatic methods of species identification on the basis of various markers measurable in stacks of CT images. Possible markers could include knot distribution within the stem, knot size, inclination and density. Since a simple grey level thresholding was effective for segmenting the knots, we decided to focus our efforts in this study on the identification of individual knots and on the validation of knot detection and measurements. On the other hand, many references found in the literature focus on the segmentation of CT images alone (which would be the first step of a more complete knot detection algorithm) without ultimately providing a method to detect each knot individually. The accuracy results are therefore presented in the form of percentages of correctly classified pixels, which are not easy to interpret by the end-users.

The percentage of detected knots (detection rate) is a more powerful criterion that is widely used in studies about individual knot detection. It is important to associate this rate with the corresponding percentage of false alarms (i.e., the number of invalid detections divided by the total number of detected knots). Our detection rates (obtained on the basis of a total of 428 manually detected knots) ranged between 71 and 100\%, depending on the beam ( $85 \%$ for all beams together), with no false alarms (i.e., all the $3 \mathrm{D}$ components identified as being knots by the algorithm were actual knots, even if they were not all manually measured), which was comparable to the results found in the literature (see Section 2). Our algorithm was 
particularly efficient for detecting even small branches while maintaining a zero false alarm level.

Relatively few validation results are available in the literature with respect to the automatic measurement of knots, especially their size and inclination. This specific point was particularly emphasized in this study. Diameter is the most widely measured and studied knot characteristic. A total of four references provided quantitative results for diameter measurements (Grundberg and Grönlund, 1992; Oja, 2000; Nordmark, 2003; Andreu and Rinnhofer, 2003a). However, validation methods were highly variable (see Section 2). In the present work, we obtained error means and SD of -1.8 (2.9) mm, which could be considered to be very accurate. No quantitative results were found in the literature regarding knot inclination, length or volume measurements. The accuracies obtained by applying our algorithm for the automatic measurements of inclination and volume were satisfactory. The knot length measurement was the least accurate. As shown in Section 4, this lack of accuracy generally occurred for small-diameter knots that could lead to fragmented 3D components due to the thresholding. Some improvements such as a radial dilatation of the $3 \mathrm{D}$ components toward the outside of the stem or the connexion of the 3D components on the basis of their azimuth could solve most of the problems. These ideas have not yet been tested in the present version of our algorithm.

As reported above, some authors (Oja, 2000; Nordmark, 2003; Andreu and Rinnhofer, 2003a; Baumgartner et al., 2010) validated their algorithm by comparison with manual measurements made on real boards or cross-sections. We chose to validate our results by comparison with manual measurements 
performed on original CT images. The reason is that we consider that the comparison between knot borders visible on colour images (i.e., based on wood colour variations) and on corresponding CT images (i.e., based on wood density variations) is a distinct problem, totally independent of the algorithm performance, and which should be studied separately.

In our study, the manual measurements of knot diameters were performed on CT images, i.e., in a transversal plane, whereas the automatic measurements were performed by using the 3D distance transform method that gave the minimum diameter at the knot profile location where the diameter was maximum. That implies to hypothesize that the knot section is circular or larger in the longitudinal direction than in the transverse direction. For Norway spruce, a ratio of 1.057 between diameters measured vertically and horizontally was reported by Merkel (1967) in Skovsgaard (1988), which represents a very slight ovality.

Finally, regardless of the type of images being dealt with, manual measurements are prone to subjectivity. Although knots are easily visible on images, it is not easy to accurately determine the borders between knots and the surrounding wood (Nordmark, 2005).

It should be observed that the use of the 3D distance map offers other potential geometric feature extractions such as the knot diameter profile. Such a feature could be available after defining a surface tracking algorithm (by using, for example, the tracking discrete surface algorithm from the DGtal (2011) library) and by focusing on the principal inertia axis.

In the current version of the algorithm, the inclination was defined as the angle between the horizontal plane and the line linking the starting point 
and the end point of the knot, both for manual and automatic measurements. This definition was totally satisfactory in relation to the way the inclination was used in this study, whereas it is questionable from a biological point of view since it depends on the length of the knot and on the stem diameter. The definitions that are often used in existing biological studies about the distribution of knot inclinations within trees (e.g., Colin et al., 1993; Makinen and Colin, 1998; Achim et al., 2006) are questionable for similar reasons: the branch inclination is measured outside of the stem for practical reasons and therefore depends on the stem diameter. CT image analysis makes it possible to non-destructively investigate the inner part of the stem, and it would be more relevant to measure inclination in the first part of the knot that is not visible outside of the stem. In further versions of the algorithm, additional definitions of the inclination will be added to the outputs.

A question arose about the sensitivity of our algorithm to the longitudinal and transversal resolutions of CT images. For example, Schmoldt et al. (1998b) compared the results obtained with an artificial neural network for two transversal resolutions of $1 \mathrm{~mm} /$ pixel and $3 \mathrm{~mm} /$ pixel. No significant difference was observed. In our case, the results obtained for beam $\# 1$ are better than for the other beams. This could be due to the fact that beam \#1 was scanned with a longitudinal resolution about three times better than the other beams. This specific point should be further investigated by scanning some materials with different resolutions and by comparing the results of the knot detection, but it has not yet been done due to cost and time considerations.

The detection failures due to the merging of several knots within the 
same component at the location of their connexion to the tree pith could be easily solved by using a black circular mask of $10 \mathrm{~mm}$ in diameter around the pith. Indeed, among the 21 knots that were not detected because they were connected together at the pith location (Section 4.1), 20 could be detected by using such a mask, leading to a detection rate of $91 \%$ on average (compared to $85 \%$ without using the circular mask). However, this method is quite rough, depending on the mask diameter, and more subtle methods should exist, perhaps based on skeletonisation, in order to find the location where the knots are connected together.

Several authors (e.g., Funt and Bryant, 1987; Andreu and Rinnhofer, 2003a; Nordmark, 2005; Rojas et al., 2006; Wei et al., 2009) encountered difficulties in detecting knots in the presence of high moisture content or sapwood (when it was visible) on CT images, especially when knots were connected to sapwood because of comparable density levels. This major problem is still unresolved in the literature. For example, Rojas et al. (2007) demonstrated the effect of moisture content on the accuracy of sapwood detection in sugar maple logs. In our study, the material was not fresh, but some remaining areas of high moisture content led to the merging of several knots within the same 3D component. Longuetaud (2005) proposed a method to overcome this problem but without actual implementation. Further developments of our algorithm will be devoted to this specific problem with the objective of applying the algorithm to fresh beams or logs.

Since cross-validation was used in this study, the method was not applied to a true independent validation sample. Nevertheless a small log (approximately $15 \mathrm{~cm}$ in diameter $\times 100 \mathrm{~cm}$ in length, taken from a 30-year-old spruce 
tree) for which the manual measurements were available was processed using the overall upper bounds given in the Materials and Methods section. The results were quite satisfactory since 73 of the 74 knots measured in this log were successfully detected without any false alarm. The $\mathrm{R}^{2}$ between manual and automatic measurements was $0.94,0.96,0.34$ and 0.91 for knot inclination, maximal diameter, length and volume, respectively. The results were particularly accurate for maximal diameter, with an error mean and SD of $0.0(0.9) \mathrm{mm}$.

\section{Conclusion}

A fully automated algorithm was developed for the detection of knots within silver fir and Norway spruce beams or logs. The detection was nondestructive since it was based on the analysis of CT images acquired by a medical X-ray CT scanner. The algorithm detected and measured knots directly in 3D, based on a connex component analysis and a 3D distance transform.

The algorithm was able to detect a total of $85 \%$ of 428 knots in seven silver fir and Norway spruce beams (91\% when applying a special process to disconnect knots when they were connected together at the pith location). Particular attention was paid to the automatic measurements of knot characteristics: inclination, diameter, length and volume. The comparison with manual measurements resulted in an $\mathrm{R}^{2}$ of $0.86,0.87,0.59$ and 0.86 for inclination, maximum diameter, length and volume, respectively.

This study could be extended in the future to solve the problem of the connection of knot components together at the pith location or due to the presence 
of an area of high moisture content, to validate and adapt the algorithm to other species, and to apply the algorithm to whole stems in order to study the distribution of knot characteristics within trees.

\section{References}

Achim, A., Gardiner, B., Leban, J. M., Daquitaine, R., 2006. Predicting the branching properties of Sitka spruce grown in Great Britain. New Zealand Journal of Forestry Science $36(2 / 3)$.

Aguilera, C., Sanchez, R., Baradit, E., 2008a. Detection of knots using X-ray tomographies and deformable contours with simulated annealing. Wood Research 53 (2), 57-66.

Aguilera, C., Sanchez, R., Baradit, E., 2008b. Internal wood inspection with active contour using data from CT scanning. Wood Research 53 (4), 13-22.

Andreu, J. P., Rinnhofer, A., 2003a. Modeling knot geometry in Norway spruce from industrial CT images. In: Bigün, J., Gustavsson, T. (Eds.), Proceedings of Image Analysis, 13th Scandinavian Conference (SCIA). Vol. 2749 of Lecture Notes in Computer Science. Springer-Verlag Berlin, Halmstad, Sweden, pp. 786-791.

Andreu, J. P., Rinnhofer, A., 2003b. Modeling of internal defects in logs for value optimization based on industrial CT scanning. In: Fifth International Conference on Image Processing and Scanning of Wood. Bad Waltersdorf, Austria, pp. 141-150. 
Baumgartner, R., Brüchert, F., UH, S., 2010. Knots in CT scans of Scots pine logs. In: The Future of Quality Control for Wood \& Wood Products, 4-7th May 2010, Edinburgh The Final Conference of COST Action E53.

Bhandarkar, S., Faust, T. D., Tang, M., 1996. A system for detection of internal log defects by computer analysis of axial CT images. In: Third IEEE Workshop on Applications of Computer Vision WACV'96. Sarasota, Florida, USA, pp. 258-263.

Bhandarkar, S. M., Faust, T. D., Tang, M., 1999. CATALOG: a system for detection and rendering of internal log defects using computer tomography. Machine Vision and Applications 11 (4), 171-190.

Bhandarkar, S. M., Luo, X. Z., Daniels, R., Tollner, E. W., 2006. A novel feature-based tracking approach to the detection, localization, and 3-D reconstruction of internal defects in hardwood logs using computer tomography. Pattern Analysis and Applications 9 (2-3), 155-175.

Bhandarkar, S. M., Luo, X. Z., Daniels, R. F., Tollner, E. W., 2008. Automated planning and optimization of lumber production using machine vision and computed tomography. Ieee Transactions on Automation Science and Engineering 5 (4), 677-695.

Björklund, L., 1997. The interior knot structure of Pinus sylvestris stems. Scandinavian Journal of Forest Research 12 (4), 403-412.

Björklund, L., Petersson, H., 1999. Predicting knot diameter of Pinus sylvestris in Sweden. Scandinavian Journal of Forest Research 14 (4), 376384 . 
Chang, S., September 1992. External and internal defect detection to optimize cutting of hardwood logs and lumber. Tech. rep.

Colin, F., Houllier, F., 1991. Branchiness of Norway spruce in north-eastern France: modelling vertical trends in maximum nodal branch size. Annales des Sciences Forestieres 48, 679-693.

Colin, F., Houllier, F., 1992. Branchiness of Norway spruce in northeastern France: predicting the main crown characteristics from usual tree measurements. Annales des Sciences Forestieres 49, 511-538.

Colin, F., Houllier, F., Joannes, H., Haddaoui, A., 1993. A model of the vertical distribution of diameters, angles and numbers of branches of three Picea abies provenances. Silvae Genetica $42(4 / 5)$.

Colin, F., Mothe, F., Freyburger, C., Morisset, J.-B., Leban, J.-M., Fontaine, F., 2010. Tracking rameal traces in sessile oak trunks with X-ray computer tomography: biological bases, preliminary results and perspectives. Treesstructure and Function 24 (5), 953-967.

Courbet, F., Sabatier, S., Guedon, Y., 2007. Predicting the vertical location of branches along Atlas cedar stem (Cedrus atlantica Manetti) in relation to annual shoot length. Annals of Forest Science 64 (7), 707-718.

Davis, J., Som, S., Svalbe, I., Grant, J., Gold, E., Tsui, K., Wells, P., 1996. The Glass Log Project: grade evaluation and defect location using X-ray computed tomography. In: 14th World Conference on Non-Destructive Testing. Vol. Vol. 3, pages 1423 - 1426. Trends in NDE Science and Technology, New Delhi. 
de Coligny, F., Ancelin, P., Cornu, G., Courbaud, B., Dreyfus, P., Goreaud, F., Gourlet-Fleury, S., Meredieu, C., Saint-Andre, L., 2003. CAPSIS: Computer-aided projection for strategies in silviculture: Advantages of a shared forest-modelling platform. In: Amaro, A., Reed, D., Soares, P. (Eds.), Modelling Forest Systems. IUFRO 4 01; IUFRO 4 11, pp. 319323, workshop on Interface between Reality, Modelling and the Parameter Estimation Process, Sesimbra, Portugal, Jun. 02-05, 2002.

DGtal, 2011. DGtal: Digital geometry tools and algorithms library. http: //liris.cnrs.fr/dgtal.

Flood, K., Danielsson, P.-E., Seger, M. M., 2003. On 3D segmentation of knots in 3D-volume data acquired from X-ray linear cone-beam scanning. In: Fifth International Conference on Image Processing and Scanning of Wood. Bad Waltersdorf, Austria, pp. 151-160.

Freyburger, C., Longuetaud, F., Mothe, F., Constant, T., Leban, J.-M., 2009. Measuring wood density by means of X-ray computer tomography. Annals of Forest Science 66 (8).

Funt, B. V., 1985. A computer vision system that analyzes CT-scans of sawlogs. In: Proceedings of IEEE Conference on Computer Vision and Pattern Recognition. San Francisco, California, pp. 175-177.

Funt, B. V., Bryant, E. C., 1987. Detection of internal log defects by automatic interpretation of computer tomography images. Forest Products Journal 37 (1), 56-62. 
Grundberg, S., Grönlund, A., 1992. Log scanning - extraction of knot geometry. In: The 1st International Seminar/Workshop on Scanning Technology and Image Processing on Wood. Skellefteå, Sweden.

Hagman, P. O. G., Grundberg, S. A., 1995. Classification of Scots pine (Pinus sylvestris) knots in density images from CT scanned logs. Holz Als RohUnd Werkstoff 53 (2), 75-81.

Hailey, J. R., Morris, P. I., 1987. Application of scanning and imaging techniques to assess decay and wood quality in logs and standing trees. In: Application of scanning and imaging techniques to assess decay and wood quality in logs and standing trees. Forestry Canada/Alberta Forest Service (Canada-Alberta Forest Resource Development Agreement), Edmonton, Alberta Canada, p. 48.

He, J., 1997. A comparison of artificial neural network classifiers for analysis of CT images for the inspection of hardwood logs. Master thesis.

Hein, S., 2008. Knot attributes and occlusion of naturally pruned branches of fagus sylvatica. Forest Ecology and Management 256 (12), 2046-2057.

Heuret, P., Barthelemy, D., Guedon, Y., Coulmier, X., Tancre, J., 2002. Synchronization of growth branching and flowering processes in the south american tropical tree Cecropia obtusa (Cecropiaceae). American Journal of Botany 89 (7), 1180-1187.

Houllier, F., Leban, J., Colin, F., JUN 1995. Linking growth modeling to timber quality assessment for Norway spruce. Forest Ecology and Management $74(1-3), 91-102$. 
Ikonen, V.-P., Kellomaki, S., Peltola, H., 2009. Sawn timber properties of Scots pine as affected by initial stand density, thinning and pruning: a simulation based approach. Silva Fennica 43 (3), 411-431, 6th IUFRO Workshop on Connection between Forest Resources and Wood Quality, Koli Natl Pk, Joensuu, Finland, Jun. 08-14, 2008.

Jaeger, M., Leban, J.-M., Borianne, P., Chemouny, S., Saint-André, L., 1999. 3D stem reconstruction from CT scan exams. From log external shape to internal structures. In: Workshop IUFRO. La Londe-Les-Maures.

Kershaw, Jr., J. A., Benjamin, J. G., Weiskittel, A. R., 2009. Approaches for modeling vertical distribution of maximum knot size in black spruce: A comparison of fixed- and mixed-effects nonlinear models. Forest Science $55(3), 230-237$.

Lemieux, H., Beaudoin, M., Zhang, S., 2001. Characterization and modeling of knots in black spruce (Picea mariana) logs. Wood and Fiber Science $33(3), 465-475$.

Lemieux, H., Samson, M., Usenius, A., 1997. Shape and distribution of knots in a sample of Picea abies logs. Scandinavian Journal of Forest Research $12,50-56$

Li, P., Abbott, A. L., Schmoldt, D. L., 1996. Automated analysis of CT images for the inspection of hardwood logs. In: The 1996 IEEE International Conference on Neural Networks (ICNN). Washington, DC, USA.

LibQGLViewer, 2011. LibQGLViewer Library. http://www.libqglviewer . com. 
Longuetaud, F., 2005. Détection et analyse non destructive de caractéristiques internes de billons d'Epicéa commun (Picea abies (L.) KARST.) par tomographie à rayons X. Doctoral thesis.

Longuetaud, F., Leban, J.-M., Mothe, F., Kerrien, E., Berger, M.-O., 2004. Automatic detection of pith on CT images of spruce logs. Computers and Electronics in Agriculture 44 (2), 107-119.

Longuetaud, F., Mothe, F., Leban, J.-M., 2007. Automatic detection of the heartwood/sapwood boundary within Norway spruce (Picea abies (L.) Karst.) logs by means of CT images. Computers and Electronics in Agriculture 58 (2), 100-111.

Makinen, H., Colin, F., 1998. Predicting branch angle and branch diameter of Scots pine from usual tree measurements and stand structural information. Canadian Journal of Forest Research-Revue Canadienne De Recherche Forestiere 28 (11), 1686-1696.

Malaterre, M., 2008. GDCM Reference Manual. http://gdcm. sourceforge.net/gdcm.pdf, 1st Edition.

Mayer, D. G., Butler, D. G., 1993. Statistical validation. Ecological Modelling 68 (1-2), 21-32.

Meredieu, C., Caraglio, Y., 1998. Cernes manquants et houppier vivant chez le pin laricio (Pinus nigra Arn. ssp. laricio (Poir.) Maire). Canadian Journal of Botany-revue Canadienne De Botanique 76 (12), 2051-2060.

Meredieu, C., Colin, F., Herve, J., 1998. Modelling branchiness of Corsican 
Pine with mixed-effect models (Pinus nigra Arnold ssp. laricio (Poiret) Maire). Annales des Sciences Forestières 55 (3), 359-374.

Merkel, O., 1967. Der Einfluss des Baumabstandes auf die Aststärke der Fichte. Allgemeine Forst Und Jagdzeitung 138, 113-125.

Moberg, L., 1999. Variation in knot size of Pinus sylvestris is in two initial spacing trials. Silva Fennica 33 (2), 131-144.

Nordmark, U., 2002. Knot identification from CT images of young Pinus sylvestris sawlogs using artificial neural networks. Scandinavian Journal of Forest Research 17 (1), 72-78.

Nordmark, U., 2003. Models of knots and log geometry of young Pinus sylvestris sawlogs extracted from computed tomographic images. Scandinavian Journal of Forest Research 18, 168-175.

Nordmark, U., 2005. Value recovery and production control in the forestrywood chain using simulation technique. Doctoral thesis, l'auteur parle des difficultés de la détection des noeuds dans l'aubier par seuillage (il cite d'autres auteurs qui ont souligné cette difficulté tels que Andreu et Flood) mais parle de la capacité de l'oeil humain de distinguer les noeuds dans l'aubier. C'est pourquoi il s'orriente vers une méthode par réseau de neurones.

Oja, J., 1996. Validation of knot models on Norway spruce. In: Second IUFRO Workshop WP S 5.01-04. "Connection between silviculture and wood quality through modelling approaches and simulation software". South Africa. 
Oja, J., 2000. Evaluation of knot parameters measured automatically in CTimages of Norway spruce (Picea abies (L.) Karst.). Holz als Roh- und Werkstoff 58 (5), $375-379$.

Passo, A., Puntieri, J., Barthelemy, D., 2002. Trunk and main-branch development in Nothofagus pumilio (Nothofagaceae): a retrospective analysis of tree growth. Canadian Journal of Botany 80 (7), 763-772.

Pietikäinen, M., 1996. Detection of knots in logs using x-ray imaging. Ph.D. thesis.

QT, 2011. Qt Development Frameworks. http://qt.nokia.com.

R Development Core Team, 2009. R: A language and environment for statistical computing. R Foundation for Statistical Computing, Vienna, Austria, ISBN 3-900051-07-0.

URL http://www.R-project.org

Rasband, W., 2010. ImageJ. U. S. National Institutes of Health, Bethesda, Maryland, USA, http://rsb.info.nih.gov/ij.

URL http://rsb.info.nih.gov/ij

Rojas, G., 2005. Détection des défauts internes dans les billes d'Erable à sucre à l'aide d'un scanneur à rayons X. Doctoral thesis.

Rojas, G., Beauregard, R., Hernandez, R. E., Verret, D., Condal, A., 2007. Effect of moisture content variation on CT image classification to identify internal defects of sugar maple logs. Forest Products Journal 57 (4), 38-43. 
Rojas, G., Condal, A., Beauregard, R., Verret, D., Hernandez, R. E., 2006. Identification of internal defect of sugar maple logs from CT images using supervised classification methods. Holz Als Roh-Und Werkstoff 64 (4), 295303.

Saito, T., Toriwaki, J.-I., 1994. New algorithms for euclidean distance transformation of an n-dimensional digitized picture with applications. Pattern Recognition 27 (11), 1551 - 1565.

URL http://www.sciencedirect.com/science/article/ B6V14-48MPN3T-19S/2/e696034f9dc2c99356a49beeb111b91d

Samson, M., 1993. Modelling of knots in logs. Wood Science and Technology 27 (6), 429-437.

Samson, M., Bindzi, I., Kamoso, L., 1996. Mathematical representation of knots in tree trunks. Canadian Journal of Forest Research 26 (2), 159-165.

Sanderson, C., 2010. Armadillo: An open source C ++ linear algebra library for fast prototyping and computationally intensive experiments. Technical Report, NICTA, http://arma.sourceforge.net/.

Sarigul, E., Abbott, A. L., Schmoldt, D. L., 2003. Rule-driven defect detection in CT images of hardwood logs. Computers and Electronics in Agriculture 41, 101-119.

Schad, K. C., Schmoldt, D. L., Ross, R. J., 1996. Nondestructive methods for detecting defects in softwood logs.

Schmoldt, D. L., He, J., Abbott, A. L., 1998a. A comparison of several artificial neural network classifiers for CT images of hardwood logs. In: Engi- 
neering, S.-T. I. S. f. O. (Ed.), Machine Vision Applications in Industrial Inspection VI. Vol. 3306. San Jose, California.

Schmoldt, D. L., He, J., Abbott, A. L., 1998b. Classifying features in CT imagery: accuracy for some single and multispecies classifiers. In: The 3rd International Seminar/Workshop on Scanning Technology and Image Processing on Wood. Skellefteå, Sweden.

Schmoldt, D. L., Li, P., Abbott, A. L., 1996. A new approach to automated labeling of internal features of hardwood logs using CT images. Review of Progress in Quantitative Nondestructive Evaluation 15, 1883-1890, le prétraitement est bien détaillé.

Seifert, T., Nickel, M., Pretzsch, H., 2010. Analysing the long-term effects of artificial pruning of wild cherry by computer tomography. Trees.

Skovsgaard, J. P., 1988. Branch thickness in unthinned stands of Sitka spruce (Picea sitchensis (Bong.) Carr.). Scandinavian Journal of Forest Research $3(2)$.

Som, S., Davis, J., Wells, P., Svalbe, I., 1993. Morphology methods for processing tomographic images of wood. In: Digital Image Computing: Techniques and Applications (DICTA). Sydney, Australia, pp. 564-571.

Som, S., Svalbe, I., Davis, J., Grant, J., Gold, E., Tsui, K., Wells, P., 1995. Internal scanning of logs for grade evaluation and defect location. In: Digital Image Computing: Techniques and Applications (DICTA). Brisbane, Australia, pp. 408-413. 
Taylor, F. W., Wagner, F. G., J., McMillin, C. W., Morgan, I. L., Hopkins, F. F., 1984. Locating knots by industrial tomography - A feasibility study. Forest Products Journal 34 (5), 42-46.

Wei, Q., Chui, Y. H., Leblon, B., Zhang, S. Y., 2008a. Identification of log characteristics in computed tomography images using back-propagation neural networks with the resilient back-propagation training algorithm and textural analysis: Preliminary results. Wood and Fiber Science 40 (4), 620633.

Wei, Q., Chui, Y. H., Leblon, B., Zhang, S. Y., 2009. Identification of selected internal wood characteristics in computed tomography images of black spruce: a comparison study. Journal of Wood Science 55 (3), 175-180.

Wei, Q., Leblon, B., Chui, Y. H., Zhang, S. Y., 2008b. Identification of selected log characteristics from computed tomography images of sugar maple logs using maximum likelihood classifier and textural analysis. Holzforschung $62(4), 441-447$.

Weiskittel, A. R., Seymour, R. S., Hofmeyer, P. V., Kershaw, Jr., J. A., 2010. Modelling primary branch frequency and size for five conifer species in Maine, USA. Forest Ecology and Management 259 (10), 1912-1921.

Wells, P., Som, S., Davis, J., 1991. Automated feature extraction from tomographic images of wood. In: Digital Image Computing: Techniques and Applications (DICTA). Melbourne, Australie.

Zhu, D. P., Beex, A. A. L., 1994. Robust spatial autoregressive modeling 
for hardwood log inspection. Journal of Visual Communication and Image Representation 5 (1), 41-51.

Zhu, D. P., Conners, R. W., Araman, P. A., 1991a. 3-D signal processing in a computer vision system. In: International Conference on Systems Engineering. Fairborn, Ohio, USA.

Zhu, D. P., Conners, R. W., Araman, P. A., 1991b. CT image sequence processing for wood defect recognition. In: The Twenty-third Southeastern Symposium on System Theory. Columbia, South Carolina.

Zhu, D. P., Conners, R. W., Lamb, F., Araman, P. A., 1991c. A computer vision system for locating and identifying internal log defects using CT imagery. In: Fourth International Conference on Scanning Technology in the Wood Industry. Burlingame, California.

Zhu, D. P., Conners, R. W., Schmoldt, D. L., Araman, P. A., 1991d. CT image sequence analysis for object recognition - A rule-based 3-D computer vision system. In: International Conference on Systems, Man, and Cybernetics "Decision Aiding for Complex Systems". Charlottesville, Virginia.

Zhu, D. P., Conners, R. W., Schmoldt, D. L., Araman, P. A., 1996. A prototype vision system for analyzing CT imagery of hardwood logs. In: IEEE Transactions on Systems, Man, and Cybernetics-Part B. Vol. 26.

Zuur, A. F., Ieno, E. N., Elphick, C. S., 2010. A protocol for data exploration to avoid common statistical problems. Methods in Ecology and Evolution $1(1), 3-14$. 


\section{Acknowledgement}

1076 We would like to thank the people at the Ets. Siat-Braun who graciously 1077 supplied the beam samples, and Françoise Huber and Marie-Christine Trouy1078 Triboulot for the identification of the species. 
Table 1: Upper bounds for the three criteria that were used for each validation data set.

They were computed from the corresponding calibration data set of the cross-validation approach

\begin{tabular}{cccccc}
\hline Validation data set & Species & $\mathrm{n}_{\text {calibration }}$ & Inclination $\left(^{\circ}\right)$ & Elongation & RDA $\left({ }^{\circ}\right)$ \\
\hline Beam \#1 & fir & 298 & 52.1 & 0.26 & 16.3 \\
Beam \#2 & fir & 273 & 48.2 & 0.26 & 15.3 \\
Beam \#3 & fir & 290 & 54.0 & 0.23 & 15.0 \\
Beam \#4 & fir & 268 & 57.5 & 0.25 & 17.0 \\
Beam \#5 & spruce & 276 & 53.0 & 0.26 & 16.8 \\
Beam \#6 & spruce & 297 & 53.5 & 0.23 & 15.5 \\
Beam \#7 & spruce & 305 & 53.4 & 0.24 & 15.4 \\
\hline
\end{tabular}


Table 2: Detection rates for each validation data set and for the whole data set

\begin{tabular}{|c|c|c|c|c|}
\hline \multirow[t]{2}{*}{$\begin{array}{c}\text { Validation } \\
\text { data set }\end{array}$} & \multirow{2}{*}{$\begin{array}{l}\text { Number of } \\
\text { manually } \\
\text { measured } \\
\text { knots }\end{array}$} & \multicolumn{2}{|c|}{$\begin{array}{c}\text { Number of } \\
\text { automatically } \\
\text { detected knots }\end{array}$} & \multirow[t]{2}{*}{$\begin{array}{l}\text { Detection } \\
\operatorname{rate}^{a}(\%)\end{array}$} \\
\hline & & $\begin{array}{l}\text { manually } \\
\text { measured }\end{array}$ & $\begin{array}{c}\text { not } \\
\text { measured }\end{array}$ & \\
\hline Beam \#1 & 39 & 39 & 24 & 100 \\
\hline Beam \#2 & 70 & 64 & 16 & 91 \\
\hline Beam \#3 & 63 & 49 & 15 & 78 \\
\hline Beam \#4 & 92 & 73 & 8 & 79 \\
\hline Beam \#5 & 59 & 55 & 28 & 93 \\
\hline Beam $\# 6$ & 50 & 46 & 28 & 92 \\
\hline Beam $\# 7$ & 55 & 39 & 30 & 71 \\
\hline All beams & 428 & 365 & 149 & 85 \\
\hline
\end{tabular}

${ }^{a}$ Number of automatically detected knots that were measured divided by the number of manually measured knots 
Table 3: Accuracy of automatic measurements for each validation data set

\begin{tabular}{|c|c|c|c|c|c|c|}
\hline Variable of interest & Validation data set & $\mathrm{n}$ & $\mathrm{R}^{2}$ & RMSE & Mean error & SD error \\
\hline \multirow[t]{7}{*}{ Inclination $\left(^{\circ}\right)$} & Beam $\# 1$ & 39 & 0.98 & 4.5 & -3.6 & 2.7 \\
\hline & Beam $\# 2$ & 64 & 0.87 & 4.2 & 2.1 & 3.6 \\
\hline & Beam $\# 3$ & 49 & 0.82 & 4.0 & 1.5 & 3.7 \\
\hline & Beam \#4 & 73 & 0.75 & 2.6 & 1.2 & 2.3 \\
\hline & Beam $\# 5$ & 55 & 0.87 & 4.5 & 0.2 & 4.6 \\
\hline & Beam $\# 6$ & 46 & 0.87 & 6.9 & -5.8 & 3.8 \\
\hline & Beam $\# 7$ & 39 & 0.90 & 4.5 & -3.2 & 3.2 \\
\hline \multirow[t]{7}{*}{ Maximum diameter $(\mathrm{mm})$} & Beam $\# 1$ & 39 & 0.91 & 2.4 & -1.6 & 1.7 \\
\hline & Beam \#2 & 64 & 0.91 & 3.2 & -2.4 & 2.2 \\
\hline & Beam $\# 3$ & 49 & 0.89 & 3.1 & -2.3 & 2.1 \\
\hline & Beam \#4 & 73 & 0.94 & 2.9 & -1.4 & 2.6 \\
\hline & Beam \#5 & 55 & 0.87 & 2.7 & -0.8 & 2.6 \\
\hline & Beam $\# 6$ & 46 & 0.88 & 5.3 & -2.9 & 4.5 \\
\hline & Beam $\# 7$ & 39 & 0.68 & 4.4 & -1.3 & 4.2 \\
\hline \multirow[t]{7}{*}{ Length $(\mathrm{cm})$} & Beam $\# 1$ & 39 & 0.97 & 0.9 & -0.6 & 0.7 \\
\hline & Beam \#2 & 64 & 0.27 & 5.2 & -3.4 & 3.9 \\
\hline & Beam $\# 3$ & 49 & 0.63 & 3.7 & -2.4 & 2.8 \\
\hline & Beam \#4 & 73 & 0.42 & 3.4 & -2.0 & 2.7 \\
\hline & Beam \#5 & 55 & 0.57 & 4.5 & -2.5 & 3.8 \\
\hline & Beam $\# 6$ & 46 & 0.54 & 3.4 & -2.0 & 2.8 \\
\hline & Beam \#7 & 39 & 0.74 & 2.2 & -0.7 & 2.1 \\
\hline \multirow[t]{7}{*}{ Volume $\left(\mathrm{cm}^{3}\right)$} & Beam $\# 1$ & 39 & 0.97 & 6.5 & 3.2 & 5.7 \\
\hline & Beam \#2 & 64 & 0.95 & 5.8 & -2.9 & 5.1 \\
\hline & Beam $\# 3$ & 49 & 0.88 & 7.8 & -2.8 & 7.3 \\
\hline & Beam \#4 & 73 & 0.92 & 15.1 & 2.9 & 15.0 \\
\hline & Beam \#5 & 55 & 0.88 & 11.8 & 3.1 & 11.5 \\
\hline & Beam \#6 & 46 & 0.96 & 17.0 & 8.0 & 15.2 \\
\hline & Beam \#7 & 39 & 0.44 & 20.0 & 9.2 & 18.0 \\
\hline
\end{tabular}




\section{List of Figures}

1 General view of the scanned beams with the manual measurements. Each beam was scanned in two 1.5-m length sections that are merged in the view. The beams are orientated according to their position in the standing tree based on the counting of annual growth rings. . . . . . . . . . . . . . . . 53

2 Illustration of the 3D scan algorithm. At each step, only the two red slices need to be loaded into the system memory. The current voxel is represented in blue while the 17 neighbour voxels (part of the 26-neighbourhood) processed at each step are given in cyan. The previous processed slices are illustrated in grey, whereas the future ones are represented by empty transparent boxes. . . . . . . . . . . . . . 54

3 Illustration of the 3D distance map computed from a knot. The resulting distance map is represented by gradient colours from red (nearest points) to blue (farthest points) on the cutting plane represented in (b). . . . . . . . . . . . . . 55

4 Schematic view of the horizontal projection of a detected component and computation of starting point (SP), end point (EP), length, azimuth and radial deviation angle (RDA). . . . 56 
5 View of a whorl of beam \#2. (a) Initial CT slice with manual measurements; (b) 3D view after knot segmentation; (c) Segmented slice with a specific colour for each component; (d) Convex hull of the segmented components. Note that a component corresponding to the support table was detected but will be removed later when considering the knot criteria. . . . . . . 57

6 Knot connexion near the pith of beam \#7. (a) Initial CT slice; (b) 3D view after knot segmentation; (c) Segmented slice with a specific colour for each component. . . . . . . . . . 58

7 Knot connexion due to wet areas in beam \#4. (a) Initial CT slice; (b) 3D view after knot segmentation,; (c) Segmented slice with specific colour for each component. . . . . . . . . 58

8 Number of knots from the seven beams that were manually measured and detected (grey), manually measured and not detected (red), not manually measured but detected (blue). . . 59

9 Accuracy results for inclination, diameter, length and volume automatic measurements. The black line corresponds to the $y=x$ axis. . . . . . . . . . . . . . . . 6 60

10 Residuals for the knot length measurement as a function of the size of knots. . . . . . . . . . . . . . . . 61 


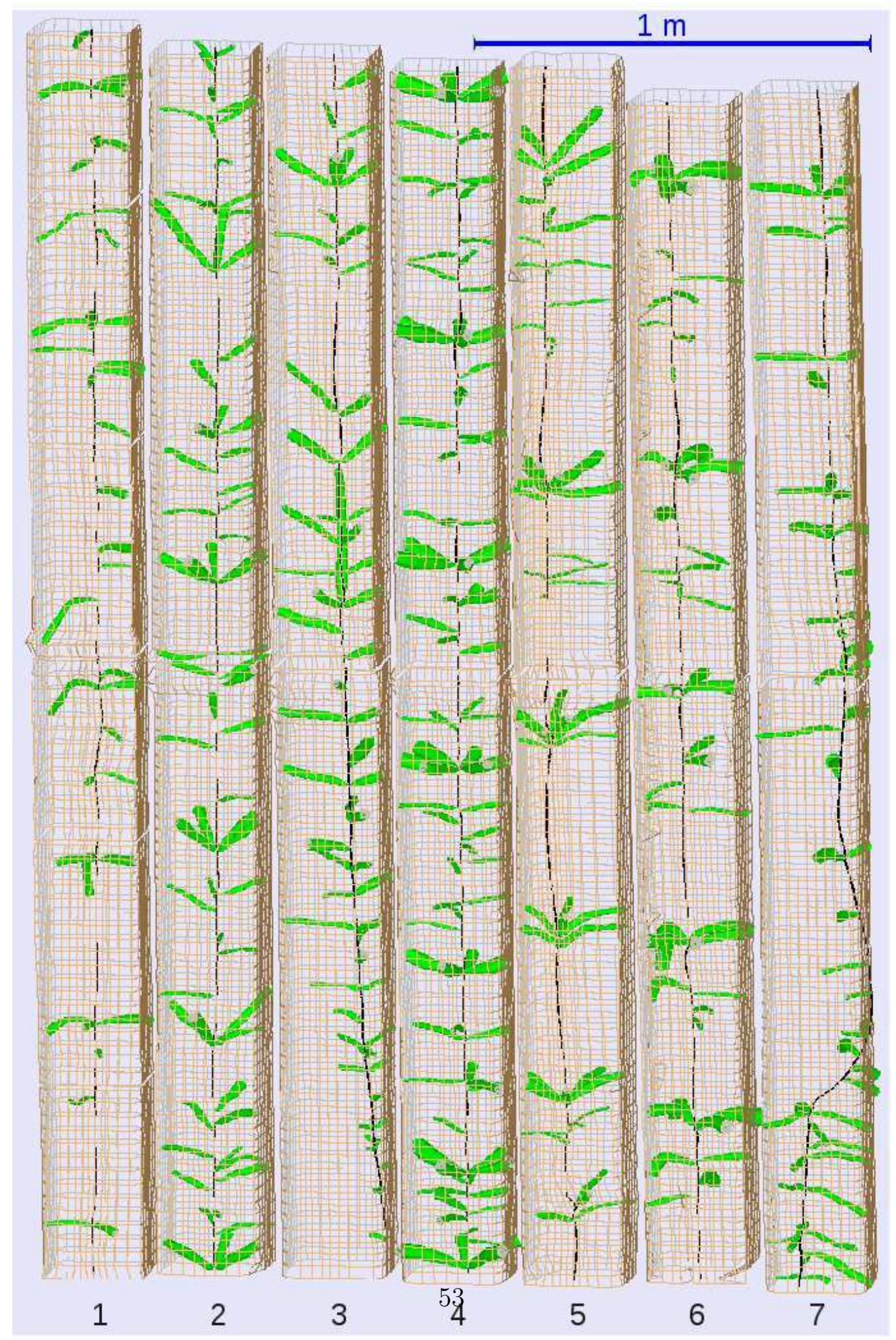

Figure 1: General view of the scanned beams with the manual measurements. Each beam was scanned in two 1.5-m length sections that are merged in the view. The beams are orientated according to their position in the standing tree based on the counting of annual growth rings. 

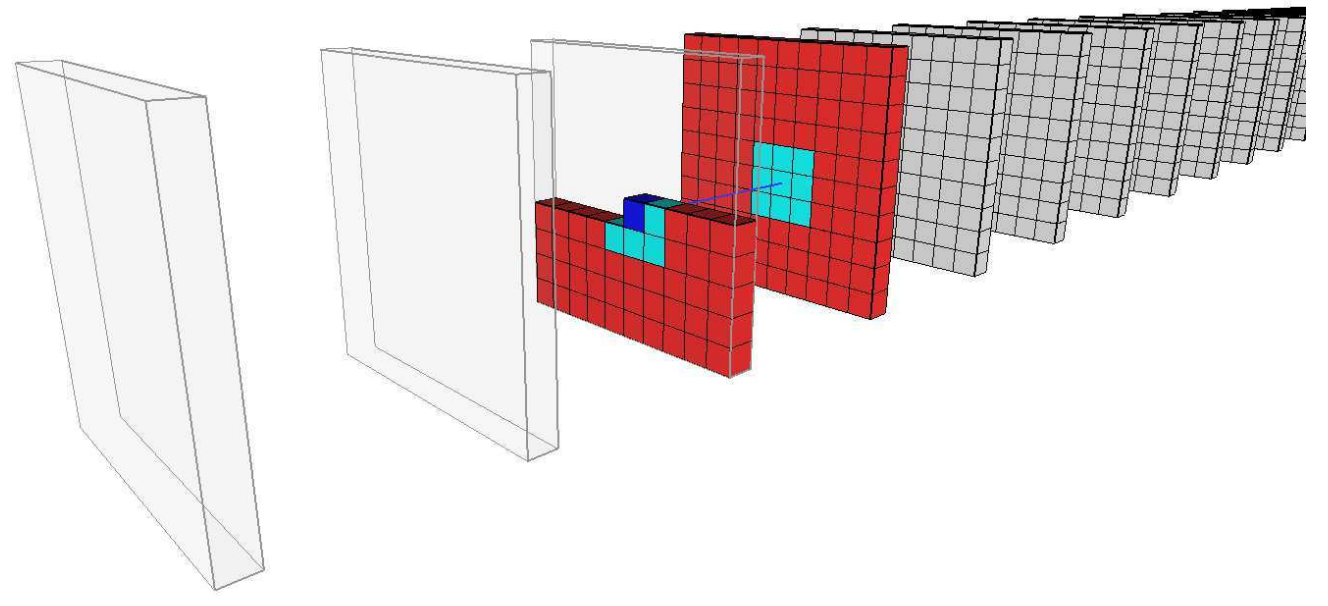

Figure 2: Illustration of the 3D scan algorithm. At each step, only the two red slices need to be loaded into the system memory. The current voxel is represented in blue while the 17 neighbour voxels (part of the 26-neighbourhood) processed at each step are given in cyan. The previous processed slices are illustrated in grey, whereas the future ones are represented by empty transparent boxes. 


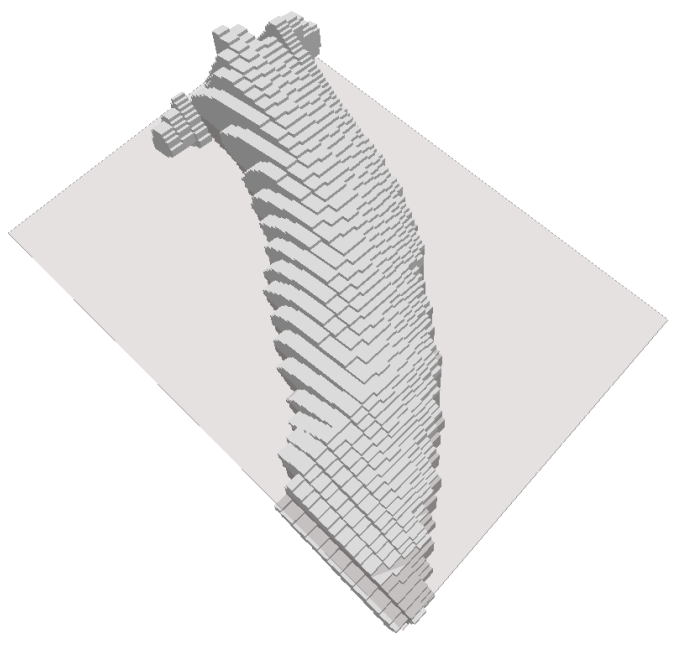

(a)

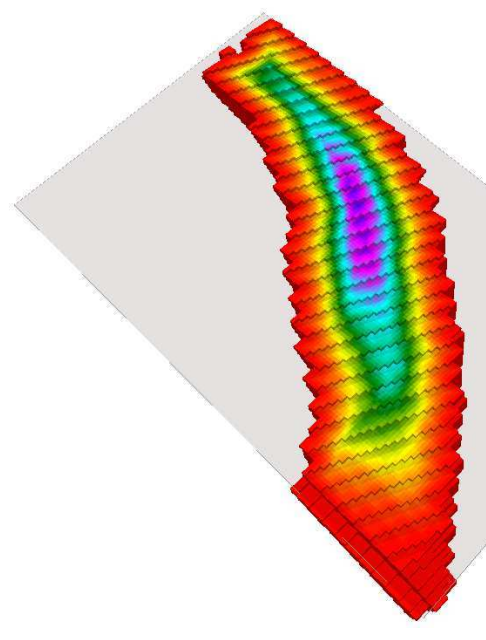

(b)

Figure 3: Illustration of the 3D distance map computed from a knot. The resulting distance map is represented by gradient colours from red (nearest points) to blue (farthest points) on the cutting plane represented in (b). 


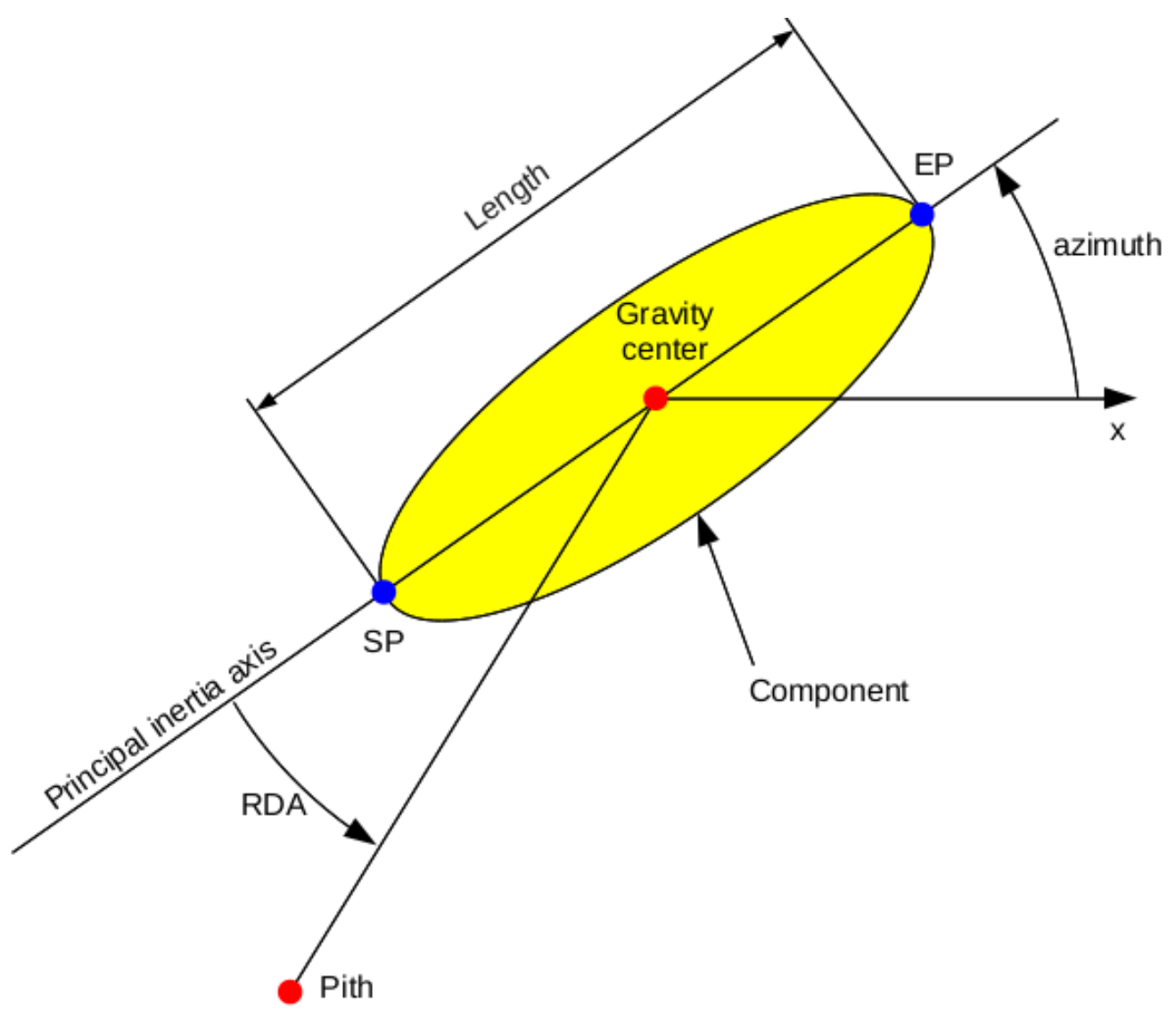

Figure 4: Schematic view of the horizontal projection of a detected component and computation of starting point (SP), end point (EP), length, azimuth and radial deviation angle (RDA). 


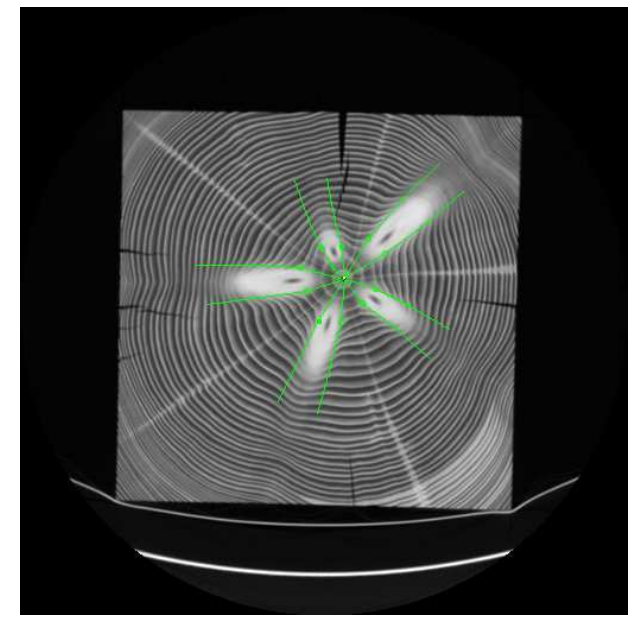

(a)

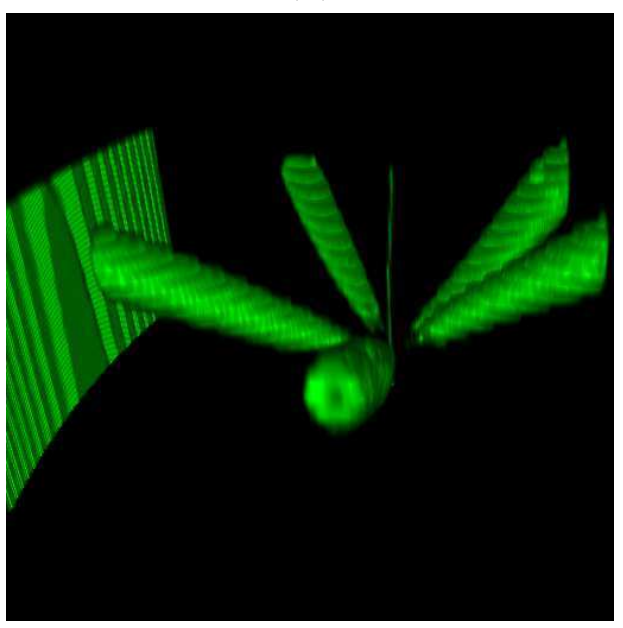

(b)

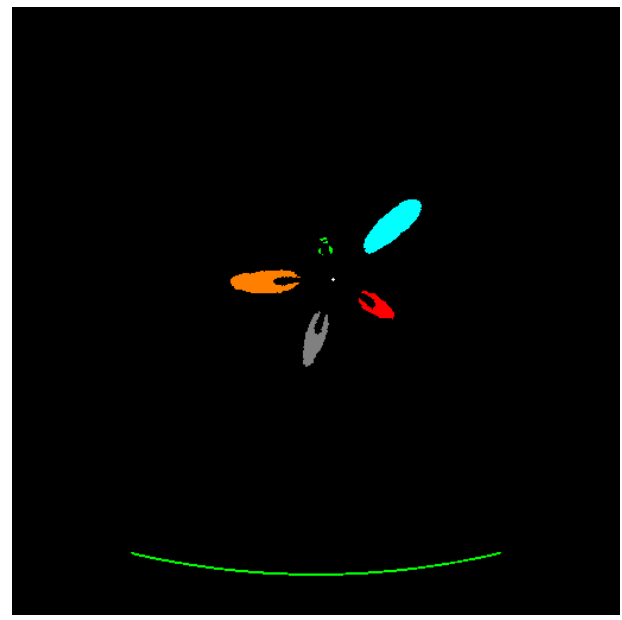

(c)

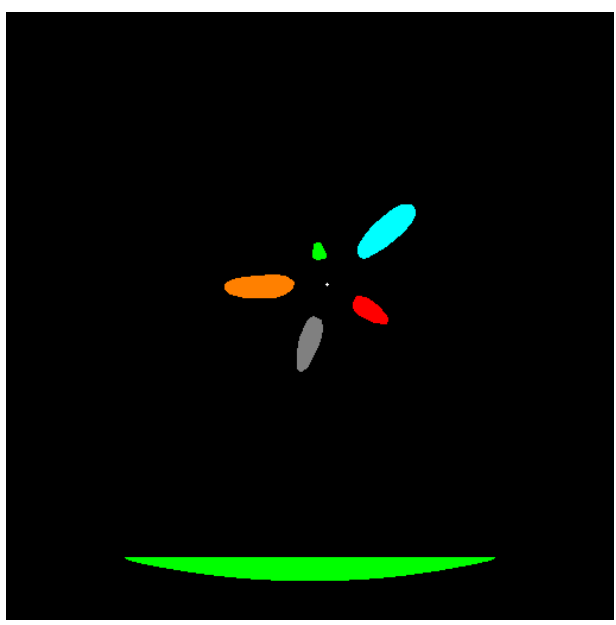

(d)

Figure 5: View of a whorl of beam \#2. (a) Initial CT slice with manual measurements; (b) 3D view after knot segmentation; (c) Segmented slice with a specific colour for each component; (d) Convex hull of the segmented components. Note that a component corresponding to the support table was detected but will be removed later when considering the knot criteria. 


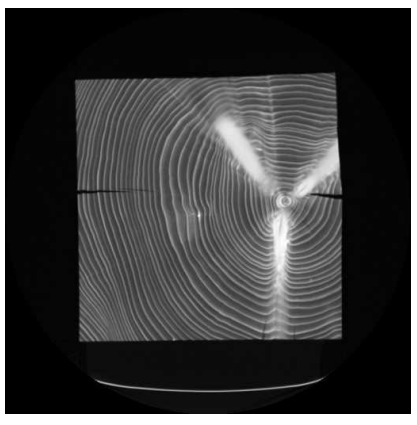

(a)

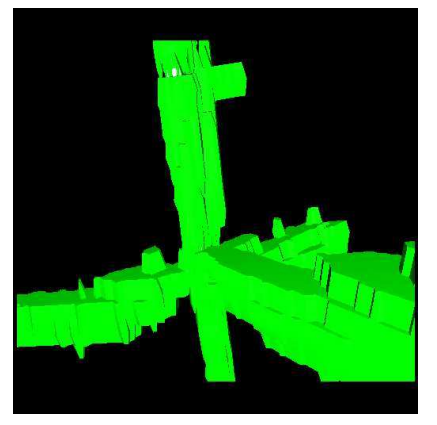

(b)

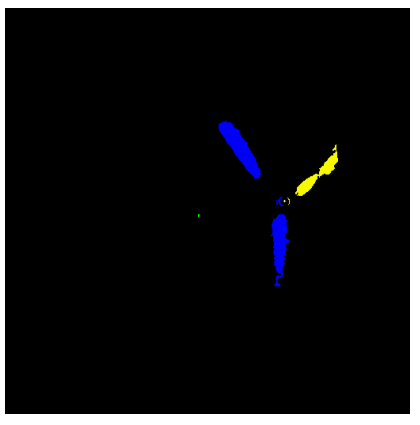

(c)

Figure 6: Knot connexion near the pith of beam \#7. (a) Initial CT slice; (b) 3D view after knot segmentation; (c) Segmented slice with a specific colour for each component.

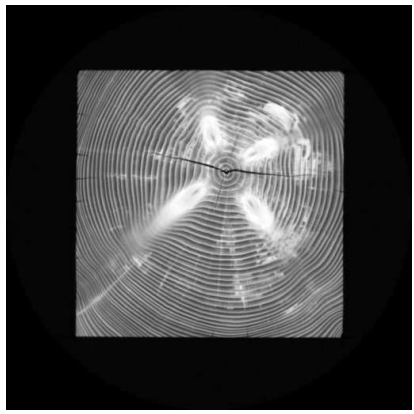

(a)

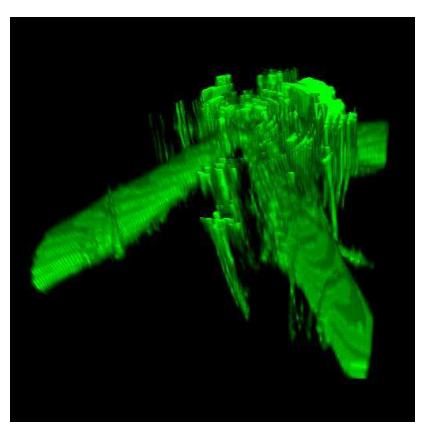

(b)

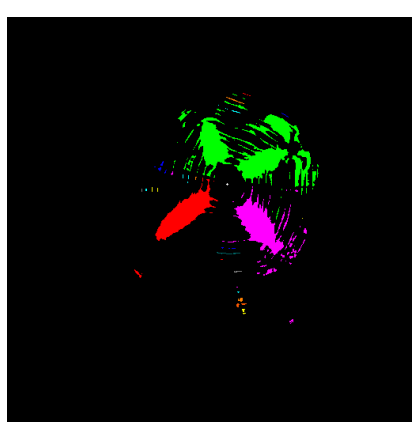

(c)

Figure 7: Knot connexion due to wet areas in beam \#4. (a) Initial CT slice; (b) 3D view after knot segmentation,; (c) Segmented slice with specific colour for each component. 


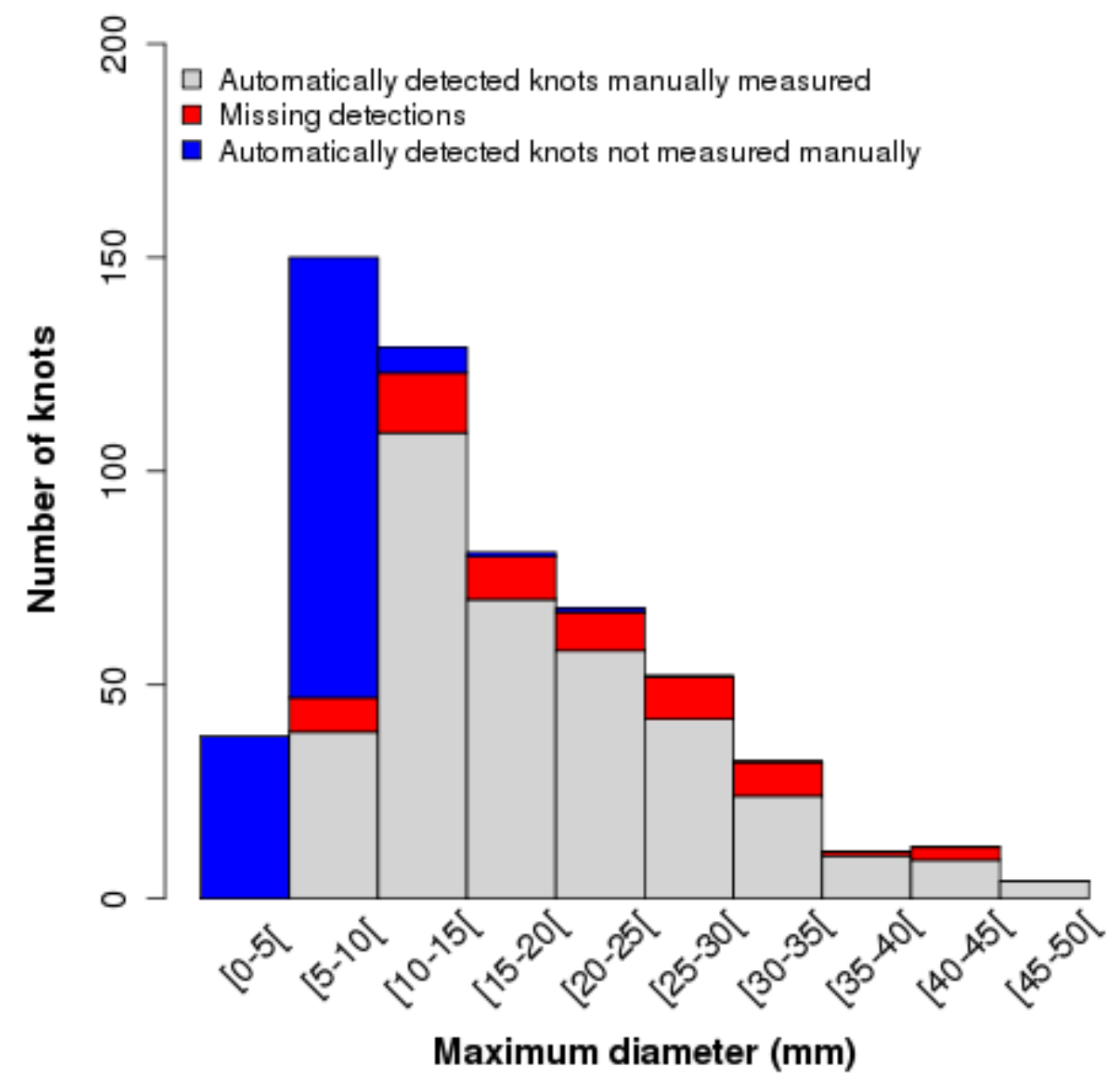

Figure 8: Number of knots from the seven beams that were manually measured and detected (grey), manually measured and not detected (red), not manually measured but detected (blue). 


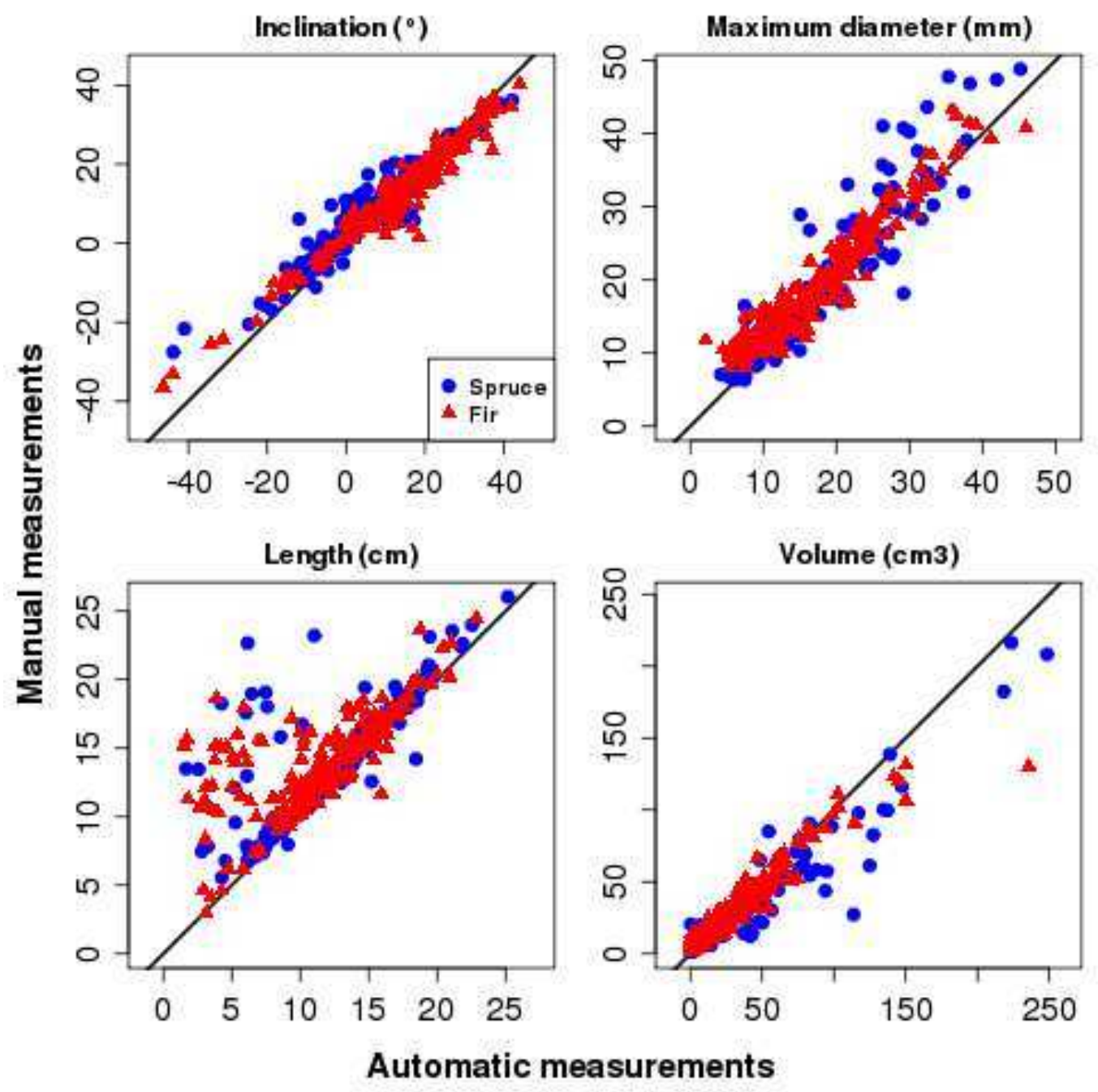

Figure 9: Accuracy results for inclination, diameter, length and volume automatic measurements. The black line corresponds to the $y=x$ axis. 


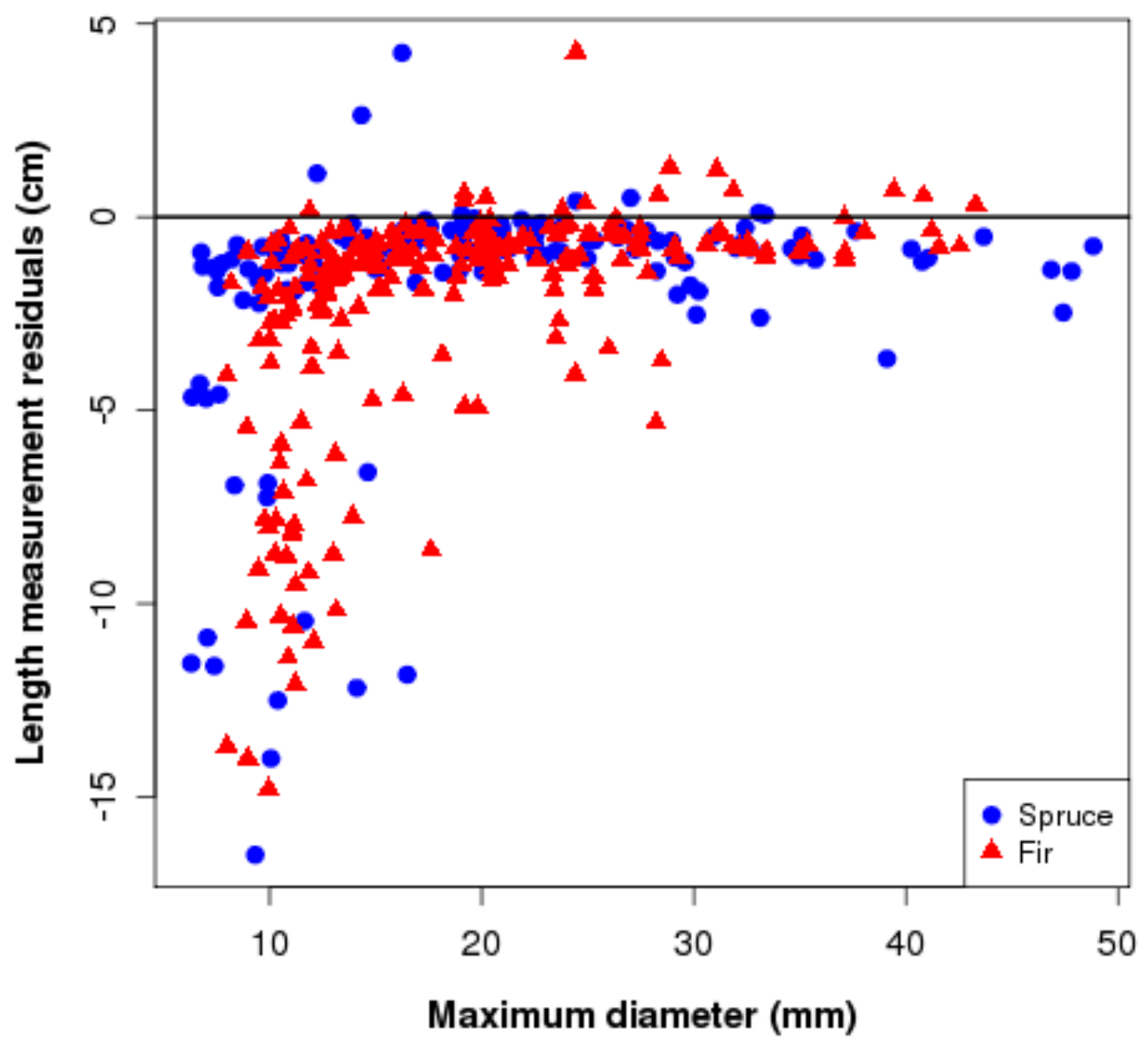

Figure 10: Residuals for the knot length measurement as a function of the size of knots. 